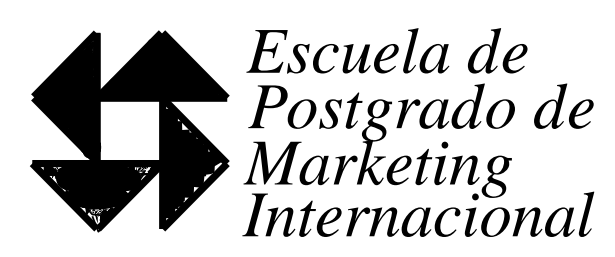

\title{
Marketing olfativo en la línea hotelera de lujo, una estrategia de creación de identidad de marca.
}

Trabajo Científico libre para la obtención del grado de Magister en Marketing Internacional de la Escuela de Postgrado de Marketing Internacional -Facultad de Ciencias Económicas

- Universidad Nacional de La Plata -

Profesor Director de Tesis:

Presentado por:

Prof. Juan Katz

Carolina Sarmiento

Pringles $13271 \mathrm{~B}$

CABA

Fecha de entrega: 29-05-2014 


\section{AGRADECIMIENTOS}

Agradezco este gran logro a Felipe mi compañero de viaje quien me ha acompañado en este proyecto de vida, a mis padres y a mi hermano quienes me han apoyado en todo y siempre han confiado en mí. También agradezco a Liesel por su esfuerzo e interés y a Juan mi tutor por creer en esta idea. 


\section{INDICE}

\section{PROLOGO \\ RESUMEN \\ OBJETIVOS \\ CAPTULO I}

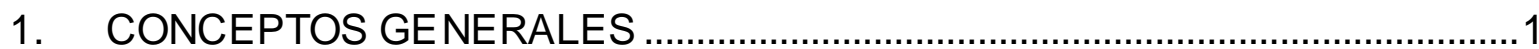

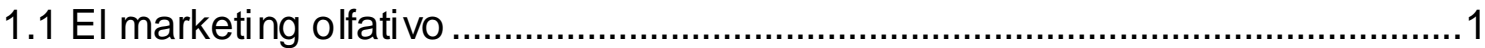

1.1.1 Importancia del marketing olfativo ……….............................................

1.2 El odotipo

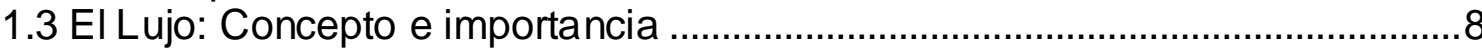

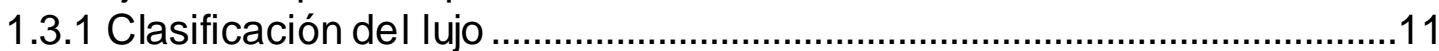

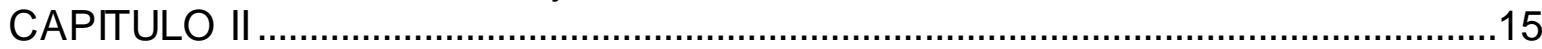

2. MARKETING OLFATIVO EN HOTELES DE LUJO ………….......................15

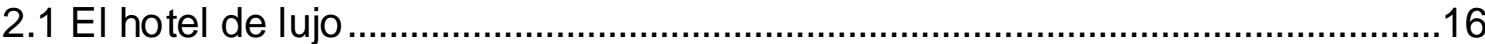

2.2 El huésped de lujo ....................................................................................25

2.3 Aplicaciones del marketing olfativo a hoteles de lujo. Del marketing en almacenes de retail a hoteles. ...............................................................................30

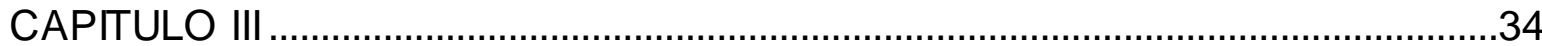

3. CREACION DE INDENTIDAD DEL HOTEL DE LUJO A TRAVÉS DEL

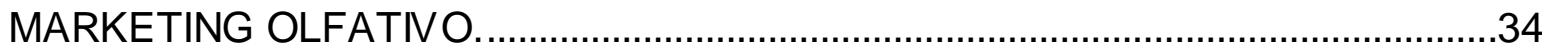

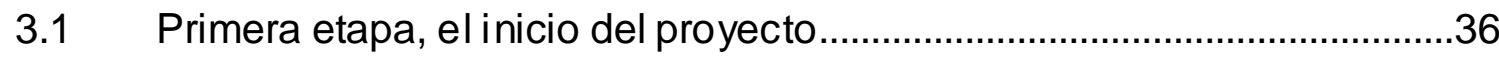

3.2 Segunda etapa, la planeación y los objetivos ……………………….........37

3.3 Tercera Etapa, la estrategia de Implementación .........................................39

3.3.1 Identificación del perfil de usuario: ........................................................40

3.3.2 Selección de las áreas del hotel que se quieren aro matizar: .............44

3.3.3 La selección de la fragancia: ..............................................................45

3.3.4 Selección del método de difusión: .......................................................47

3.4 Cuarta etapa, ejecución del proyecto, el seguimiento, el método de evaluación y el análisis de datos. ...........................................................................48

3.5 Quinta etapa de finalización y cierre ........................................................52

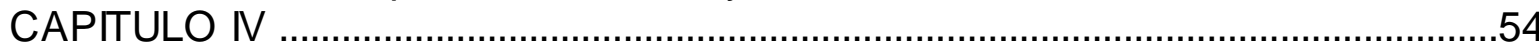

4. CASO DE APLICACIÓN: HOTEL BO BO, UN HOTEL BOUTIQUE DE LUJO. 54

4.1 Siguiendo el modelo, proceso de implementación de una fragancia en el

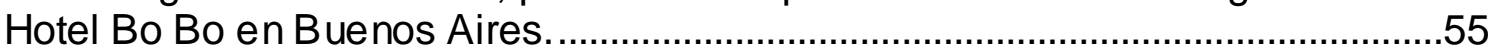

4.1.1 Primera etapa: El inicio del proyecto …….......................................55

4.1.2 Segunda etapa: La planeación y los objetivos …………………........59

4.1.3 Tercera etapa: La estrategia de implementación.................................60 
4.1.3.1 Selección de las áreas del hotel que se quieren aromatizar: .............61

4.1.3.2 La selección de la fragancia: ...............................................................63

4.1.3.3 Selección del Método de difusión: ..........................................................64

4.1.3.4 Evaluación de costos: ………………………..................................66

4.1.4 Cuarta etapa: Ejecución del proyecto, el seguimiento, el método de evaluación y el análisis de datos......................................................................66

4.1.5 Quinta etapa de finalización y cierre ................................................68

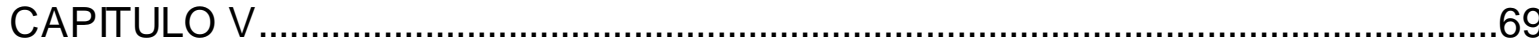

$5 \quad$ CONCLUS IONES Y RECOMENDACIONES .............................................69

5.1 Conclusiones de acuerdo a la información obtenida ...............................69

5.2 Sugerencias para futuros estudios relacionados al tema. ........................72

$5.3 \quad$ Comentarios generales y personales. ………………………................. BIBLIOGRAFIA

ANEXOS

ANEXO 1 - CARTA DE AUTORIZACION PARA LA IMPLEMENTACION DEL TRABAJO EN EL HOTEL BO BO 


\section{PROLOGO}

El marketing como disciplina es cada vez más importante dentro del marco empresarial, siendo ésta, un área clave en la generación de nuevos negocios y en la incorporación de estrategias dirigidas a usuarios y consumidores, de prácticamente todos los bienes disponibles hoy día. Con el paso del tiempo el marketing ha tenido un gran desarrollo, de manera que ha creado estrategias definidas de acuerdo a los mercados a los cuales quiere llegar, de esta forma aparece el marketing sensorial como una estrategia clara de diferenciación con la cual muchas empresas pretenden afrontar el reto de aumentar y mantener a los usuarios y clientes que cada vez son más exigentes y los mercados más competitivos.

El marketing sensorial involucra todos los sentidos con el fin de incorporarse dentro de la experiencia del usuario y/o consumidor, de forma tal que pueda generar un impacto positivo y esto repercuta en los resultados económicos y de satisfacción dentro de las organizaciones.

Dentro del marketing sensorial encontramos una categorización donde está incluido el marketing olfativo, el cual se incorpora como una estrategia enfocada a generar impacto a través del sentido del olfato; esto como consecuencia de estudios, como el de la universidad de Rockefeller en Nueva York que concluyó que "el hombre es capaz de recordar el $5 \%$ de lo que ve, el $2 \%$ de lo que escucha, el $1 \%$ de lo que toca y el $35 \%$ de lo que huele (Sutton, 2011$)^{1}$, además de otras evaluaciones realizadas al respecto de las cuales se hará mención durante el presente trabajo.

\footnotetext{
${ }^{1}$ Sutton P.. (2011). Multisensory Experiential Marketing. Head of Multisensory Innovation. Recuperado de http://eventige.com/multisensory-experiential-marketing/
} 
Para el presente trabajo se mencionará el sector de hotelería de lujo, por ser este un mercado definido al cual pueden aplicarse estrategias de marketing olfativo con el fin de crear identidad de marca.

El sector de hoteles de lujo intenta brindar una experiencia única a sus huéspedes a través de su servicio con elementos que transmitan bienestar y comodidad, en una atmósfera que pareciera exclusiva para cada uno de los que los visitan.

Es por ello, que el presente trabajo pretende servir como herramienta mediante el diseño de un modelo de desarrollo de una marca olfativa direccionada a la línea hotelera de lujo, un segmento del mercado muy interesante. De esta forma se muestra como el marketing olfativo puede considerarse como una tendencia innovadora y efectiva dentro de las estrategias de marketing que está creciendo en la actualidad.

\section{RESUMEN}

El presente trabajo comienza haciendo un recorrido por algunos conceptos generales preliminares para la temática a desarrollar, tales como en que consiste el marketing sensorial y su importancia, definición de conceptos como el odotipo, además de incluir el concepto y clasificación del lujo. De esta forma se da paso al marketing olfativo en hoteles de lujo describiendo las características de un hotel de lujo y el huésped de lujo donde se ilustran algunos ejemplos.

Una vez presentes los conceptos iniciales se abre paso a la creación de un odotipo en un hotel de lujo a través del marketing olfativo, mediante el desarrollo de un modelo que toma conceptos de marketing sensorial, en especial sobre marketing olfativo, hoteles de lujo, proyectos y temas relacionados, además de incluir información acerca de marketing sensorial olfativo y hoteles de lujo, mencionados a lo largo de los primeros capítulos. De esta forma se comienza a describir etapa a etapa los pasos a seguir cuando se quiere incorporar una marca 
olfativa en un hotel de lujo generando un modelo que comienza con la elaboración de objetivos y termina con la ejecución y evaluación de los resultados obtenidos.

De acuerdo a la información recopilada se emiten juicios referentes a la importancia de estas técnicas de marketing experimental en la creación de marcas de lujo, de esta forma se plasma un modelo de desarrollo de un aroma basado en los conceptos vistos a lo largo del presente trabajo y en información referente a la formulación de un proyecto.

Finalmente se expone un caso real de un hotel boutique de lujo en la ciudad de Buenos Aires, donde se aplica el modelo planteado como estrategia de marketing para generar un odotipo e identidad de marca en el hotel. 


\section{OBJETIVOS}

Objetivo general

- Desarrollar y aplicar un modelo de marketing olfativo a un caso en un hotel boutique, como estrategia de diferenciación e identidad mediante el análisis y la comprensión de los conceptos generales y el target de hotelería de lujo.

Objetivos específicos

- Comprender los conceptos generales de marketing olfativo, odotipo y lujo.

- Identificar el target de lujo en la línea hotelera.

- Analizar cómo ha evolucionado el marketing olfativo dentro del marketing sensorial.

- Describir algunas técnicas del marketing olfativo como estrategia de recordación de marca en la línea de hoteles de lujo.

- Desarrollar una metodología de marketing olfativo que sirva de modelo en la línea de hoteles de lujo.

- Aplicar los conceptos desarrollados a lo largo del trabajo a un caso práctico y real en un hotel de lujo. 


\section{CAPTULO I}

\section{CONCEPTOS GENERALES}

\subsection{El marketing olfativo}

"Así como logotipo, el logo olfativo, intenta expresar el perfil y los valores de la empresa, sumados a las características del público, a través del olor. Esta acción tiene un costo."

- Priscilla Paoli -

El estudio del marketing debe partir de una comprensión del concepto y del alcance que el término pueda generar, de forma que sea posible profundizar en las actividades y objetivos que se puedan lograr en las empresas donde se aplique. Siguiendo la definición de la Asociación Americana de Marketing (AMA) ${ }^{2}$ el marketing es definido como "(...) una actividad, un conjunto de instituciones y procesos de creación, comunicación, entrega e intercambio de ofertas que tienen valor para los clientes, los socios y la sociedad en su conjunto".

\footnotetext{
${ }^{2}$ AMA (Asociación Americana De Marketing). Definition of Marketing. Recuperado el 4 de diciembre de 2012 de http://www.marketingpower.com/AboutAMA/Pages/DefinitionofMarketing.aspx
} 
Debido a la globalización de los mercados, la inmensa cantidad de oferentes y el rápido cambio de las tendencias, los consumidores se han vuelto cada vez más exigentes y la fuerte competencia entre las empresas es cada vez más difícil. En consecuencia, las empresas han tenido que recurrir a nuevos elementos de apoyo que permitan generar una diferenciación clara con sus competidores en la mente de los consumidores, por medio de estrategias de comunicación que involucraran todos los sentidos, una tarea difícil de lograr.

En este proceso de comunicación, el marketing tradicional ha intentado establecer relaciones mediante el uso de los sentidos físicos, de forma que sea posible atraer, retener y generar recordación de marca en el mercado, para de esta manera aumentar las ventas, fidelizar a sus clientes y generar una imagen positiva, entre otros.

Los sentidos han sido protagonistas en las estrategias de marketing modernas debido a que a través de ellos, ha sido posible despertar el interés de los consumidores por medio de emociones generadas a través del contacto y la experiencia. Para ello, las empresas dedicadas al marketing se han puesto en la tarea de diseñar estrategias donde incluyen en sus propuestas imágenes, sonidos y aromas llamativos que les permitan generar un proceso de recordación en la mente del consumidor. Vale la pena decir que, pese a que todos los sentidos tienen importancia para el marketing, los sentidos más involucrados en las campañas de marketing han sido la vista y el oído, siendo los menos explorados, el tacto y el olfato.

Es así como el término de marketing sensorial ha surgido como un área especializada del marketing experimental, cuyo énfasis se centra en los sentidos como medio para transmitir mensajes de marca y generar recordación en los consumidores. Esto, como respuesta al rápido y creciente desarrollo de un mercado exigente y una competencia especializada en un ámbito de mercados 
globales en la que las empresas buscan salir de esquemas tradicionales y generar una imagen diferenciadora y positiva en los consumidores.

De acuerdo a Wright, Newman y Dennis (2006) ${ }^{3}$ el marketing sensorial es posible definirlo como la utilización de los estímulos y elementos que los consumidores perciben a través de los cinco sentidos para generar determinadas atmosferas. De esta forma, usando la definición anterior sería posible identificar y definir un área específica del marketing sensorial que involucre el olfato, como marketing olfativo.

De acuerdo con investigaciones de la Universidad de Rockefeller ${ }^{4}$, el sentido del olfato es uno de los sentidos que mayor impacto y poder de recordación tiene. El estudio concluyó que el hombre recuerda el $35 \%$ de lo que huele seguido del $5 \%$ de lo que ve, el $2 \%$ de lo que escucha y el $1 \%$ de lo que toca. Sin embargo pese a que el olfato es el sentido con mayor poder de recordación es el menos explorado. Es por ello que el marketing moderno cada vez presta más atención al marketing experimental y sensorial, haciendo especial énfasis en el marketing olfativo. Sutton (2011)5.

A manera de definición, podría decirse que el marketing olfativo es un conjunto de actividades encaminadas a transmitir comunicaciones claras entre consumidores y/o usuarios y las empresas, a través de la experiencia mediante el sentido del olfato. Esto, con el objetivo de lograr posicionar una marca o una idea en la mente de los consumidores, y posteriormente, lograr un mejor comportamiento de las ventas, la imagen y la recordación de marca de la empresa, entre otros objetivos.

\footnotetext{
${ }^{3}$ Wright. L T. Newman A y Dennis C. (2006). Enhancing consumer empowerment. European Journal of Marketing.ed 40, 9/10, 925-935

${ }^{4}$ Ibid Sutton (2011)

${ }^{5}$ lbid Sutton (2011).
} 


\subsubsection{Importancia del marketing olfativo}

Hace algunos años muchas empresas entre ellas los supermercados y puntos de venta hacían uso de algunas estrategias de marketing olfativo sin saberlo. Utilizaban fragancias ${ }^{6}$ para aromatizar sus locales y almacenes con el fin de hacerlos agradables y en muchos casos con el objetivo de cubrir malos olores generados por procesos o resultantes de materiales almacenados en el depósito, además de otras razones. Como consecuencia de estas actividades, las compañías comenzaron a ver que el efecto de éstas se traducía en clientes satisfechos, mejora de la imagen de la empresa, y en el aumento de las ventas, ejemplo de esto lo reveló un estudio de aplicación del modelo de marketing sensorial en una empresa chilena de retail, donde pusieron en práctica estrategias de marketing que involucraban todos los sentidos con resultados positivos reflejados en aumento de ventas y fidelización de clientes. (Arias y Díaz, 2011) ${ }^{7}$.

Empresas dedicadas al marketing han dedicado sus esfuerzos en hacer uso de estrategias enfocadas al sentido del olfato para crear una mejor comunicación con los clientes y usuarios mediante la introducción del marketing olfativo en sus campañas publicitarias, en sus puntos de venta y hasta en eventos con resultados positivos. De hecho, tal como se sugiere en Bloomberg business week $(2010)^{8}$, la implementación de estrategias de marketing olfativo en muchos casos muestran que las ventas han sido afectadas de manera positiva, y en consecuencia, los rendimientos de los inversionistas se han incrementado. Este hecho ha generado que cada día sean más las empresas que intentan incluir el uso de aromas como estrategia de marketing, y cada vez sean más las empresas en todo el mundo dedicadas al Aromarketing. Como ejemplo de aplicación de este tipo de estrategias Dunkin Donuts mostró el aumento de las ventas en un $29 \%$ tras la

\footnotetext{
${ }_{7}^{6}$ Para el presente trabajo los términos fragancia, aroma y olor tendrán el mismo significado.

${ }^{7}$ Arias Díaz, I. y Díaz Frigerio, M. (2011). Aplicación del modelo de Marketing Sensorial de Hulten, Broweus y Van Dijk a una empresa chilena de retail. Universidad de Santiago de Chile.

${ }^{8}$ Bloomberg Business Week. (2010). Scent Branding Sweeps the Fragrance Industry.
} 
implementación de una campaña por parte de la compañía donde el sentido del olfato era el protagonista, (Marketing y Finanzas, 2013) ${ }^{9}$.

De acuerdo con Wright, Newman y Dennis $(2006)^{10}$ la implementación de elementos del marketing que estimulen los sentidos en determinados ambientes, cambia la percepción del cliente, haciendo que éste le otorgue mayor importancia y le dé más valor. El sentido del olfato se ha convertido en uno de los principales actores de la obra que pretende despertar sensaciones y crear nuevas experiencias en los clientes, cuyas expectativas son cada vez más altas.

Las empresas pretenden generar lazos emocionales a través de la creación de espacios agradables que permitan relacionar el aroma con la marca y el lugar.

Estos hechos han despertado el interés de muchos y es por ello cada vez son más los centros de investigación sensorial dedicados a la investigación del sentido del olfato, entre los más reconocidos se encuentran The Sense of Smell Institute of The Fragrance Foundation, The Smell \& Taste Treatment and Research Foundation en Chicago, The Monell Center Advancing Discovery, The Center For Smell and Taste en La Universidad de Florida y la Universidad de Rockefeller, quienes han desarrollado estudios en temas relacionados con el sentido del olfato, su importancia y su fuerte influencia en el comportamiento de los consumidores.

Algunos estudios basados en test realizados a consumidores donde se involucraron fragancias como los de Gaygen y Hedge (2008) ${ }^{11}$ y llmberger $(2000)^{12}$, entre otros, han demostrado que el hombre responde frente a estímulos generados por el sentido del olfato, generando respuestas dependiendo de la situación. Esto se explica debido a que la mente recibe información a través de los

\footnotetext{
${ }^{9}$ Marketing Olfativo Tu Marca Huele Bien. Recuperado el 4 de julio de 2013 de http://www.marketingyfinanzas.net/2013/07/marketing-olfativo-tu-marca-huele-bien-2/.

${ }^{10}$ lbid Wright (2006)

${ }^{11}$ Gaygen, D y Hedge, A. (2008). Effect of acute exposure to a complex Fragrance on lexical decision. Department of Design and Environmental Analysis. Cornell University. Ithaca Estados Unidos.

12 Ilmberger, J. Heuberger, E., Mahrhorfer, C. Dessovic, H., Kowarik, D. y Buchhbauer, G. (2000). The influence of essential Oils on human Attention. Alertness.
} 
sensores olfativos y los traduce en recuerdos y reacciones a través de los otros sentidos.

Algunas Instituciones como la Universidad de Rockefeller ${ }^{13}$ en Nueva York se dedican al estudio del sentido del olfato y su influencia en diferentes áreas de la vida cotidiana del hombre. Podríamos decir que un olor en particular es capaz de transportar a una persona a otro lugar y momento de su vida. Algunos estudios realizados por esta universidad y el "Sense of Smell Institute" muestran como el sentido del olfato tiene influencia en el comportamiento.

Actualmente, el marketing olfativo está pasando de ser una de las estrategias de mayor interés por el impacto que genera. En este proceso y con el objetivo de lograr que esta herramienta sea realmente efectiva, las empresas deben tener muy claros los objetivos y valores que desean transmitir, para que de esta forma, sea posible enviar el mensaje correcto y lograr que éste sea fácilmente relacionado con la marca. En caso contrario, el mensaje podría tener el efecto negativo o transmitir una idea equivocada.

En las empresas donde se han incorporado fragancias en los puntos de venta como parte de las estrategias de marketing olfativo, se ha logrado atraer a clientes nuevos y retener a los ya existentes, por medio de la recordación lograda por el uso de una imagen olfativa atractiva. Todo esto a su vez repercute en un aumento de las ventas y de los rendimientos generados por la empresa. De acuerdo con Steven Semoff ${ }^{14}$ un estudio realizado por Nike mostro que incorporar fragancias en sus locales incrementó las compras en un $80 \%$.

\footnotetext{
${ }^{13}$ Vosshall L. y Carandini M. (2009). Sensory Systems. " Rockefeller Researchers ShowBrain Wiring For Detecting Odors May Depend On Experience" (2000) Laboratory of Neurogenetics and Behavior. The Rockefeller University. United States: Els evier Ltda. Recuperado de http://vosshall.rockefeller.edu/s mellstudy.php

${ }^{14}$ The marketer the chartered instituted of marketing. Smell sells: scent marketing (2011). Recuperado de http://www.themarketer.co.uk/archives/trends/scent-marketing/.
} 
De acuerdo a Schmitt $(2002)^{15}$, los consumidores hayan que los beneficios funcionales de un producto, tal como la calidad y la marca, son aspectos que no tienen efectos sobresalientes para un consumidor al momento de escoger hacer una compra. En consecuencia, se podría decir que los consumidores han pasado a un nivel más elevado, con expectativas más altas y más difíciles de satisfacer, en el cual las campañas de comunicación atractivas que estimulan los sentidos y generan emociones son las que marcan una experiencia diferente para el cliente.

\subsection{El odotipo}

El marketing olfativo está estrechamente relacionado con el termino odotipo, desarrollado por la publicación de José Martin Bonadeo $(2005)^{16}$, en el cual se desarrolla la historia natural del olfato y su función en la identidad de marca. Bonadeo (2005) hace referencia a la relación entre creación de marca e identidad a través del sentido del olfato y define odotipo como un término que proviene de olor y logotipo, que se traduce en el también llamado logo olfativo.

Este término es una representación gráfica que incluye símbolos e identifica a una marca, solo que en lugar de incluir símbolos visuales utiliza señales olfativas que la identifiquen y transmitan a través de éstas los valores de la misma. Quienes utilizan odotipos desarrollados pensando en lo que quiere transmitir la empresa pretenden ser recordados y reconocidos a través de un aroma.

Para el desarrollo de un odotipo que realmente represente y transmita lo que una empresa desea, es importante tener en cuenta diferentes factores como el color, la imagen, el target objetivo, los valores, entre otros, que permitan el diseño

\footnotetext{
${ }^{15}$ Smith, V. (1989). Second Edition Hosts and Guests The Antropology of tourism. Universidad de Pennsylvania.

${ }^{16}$ Bonadeo J. (2005) Odotipo Historia Natural del Olfato y su función en la Identidad de Marca. Argentina.
} 
adecuado de la fragancia y que ésta sea acorde al mensaje que se quiere transmitir.

El desarrollo y la selección del aroma correcto requiere de un amplio trabajo en el cual intervienen personas de diferentes áreas como marketing, diseño, administración y producción tanto de la empresa que quiere incorporar el logo olfativo como de la empresa dedicada al diseño de la misma. Para ello es importante realizar reuniones de equipo donde se elige el aroma, el método de difusión, el ambiente, la intensidad y todos los factores que puedan convertirse en parte del logo olfativo de la empresa. En este proceso se pueden realizar entrevistas, encuestas, sesiones de grupo, y otras actividades que permitan obtener información del target objetivo y así realizar un diseño adecuado del odotipo.

\subsection{El Lujo: Concepto e importancia}

Ir a un spa el fin de semana, pasar unas vacaciones en un hotel de alta categoría, comer en los mejores restaurantes y visitar los lugares más exclusivos pueden ser actividades que para muchos se categorizarían como lujo. Si se busca en el diccionario de la lengua española, ésta define al lujo como "riqueza, suntuosidad, abundancia de cosas no necesarias, todo aquello que supera los medios normales de alguien para conseguirlo". Sin embargo, podría decirse que lujo es también un estado de confort donde la exclusividad juega un rol primordial, mucho más importante que el precio, para ciertos grupos sociales a los que lo tradicional no les parece suficiente.

El lujo ha ido creciendo como objetivo corporativo en la producción de bienes y servicios a nivel mundial. Cada vez más, las empresas de diferentes sectores realizan esfuerzos financieros y técnicos más importantes por innovar en los 
procesos y ofrecer alternativas únicas, excitantes y personalizadas a clientes exigentes, para los cuales el precio no es un factor relevante al momento de elegir sus gastos.

En el caso del sector de lujo, los usuarios y clientes pasan por desapercibidas las campañas tradicionales, ya no se motivan con lo común, están abiertos a experimentar, a vivenciar, a sentir. El lujo hoy día, es mucho más que pagar altas sumas de dinero por un bien, es el despertar el deseo de ser exclusivo, y diferente, de tener aquello que para otros es muy difícil de obtener, lo escaso, lo único.

De acuerdo con Campuzano (2005) ${ }^{17}$ el mercado de lujo mundial corresponde a un $10 \%$ del consumo privado, porcentaje que ha ido en aumento en los últimos años, esto revelan las estimaciones hechas por la consultora Brain \& Company $(2012)^{18}$ que indican que el crecimiento del mercado de lujo a nivel global para el año 2012 se estimó en un 7\%, porcentaje que año a año toma una porción mayor del mercado global.

Si bien Campuzano (2005) categorizó el lujo en cuatro categorías: cosmética y perfumes $(38 \%)$, artículos y accesorios de cuero (16\%), joyería y relojería $(16 \%)$ y la moda (14\%), Sería posible añadir una quinta categoría que es una de las importantes y esta direccionada no solo a los productos sino al sector prestador de servicios, la experiencia de lujo.

El concepto de experiencia de lujo, podría definirse entonces como todos aquellos momentos que quisiera vivir el usuario de lujo, el cliente de lujo, quien está dispuesto a pagar elevadas cantidades de dinero en tanto pueda sentirse

\footnotetext{
${ }^{17}$ Campuzano Garcia, S. (2003). El Universo del lujo: Una Visión Global y Estratégica de los Amantes del Lujo. Madrid España:McGraw-Hill.

${ }^{18}$ Luxury goods market predicted to grow six to seven percent in 2012 , defying glo bal turmoil and spreading to new markets, according to spring update of Bain \& Company's luxury goods worldwide market study. 15 de mayo de 2012. Recuperado de Brain \& Company. http://www.bain.com/about/press/press-releases/luxurygoods-market-predicted-to-grow-six-to-seven-percent-in-2012.aspx
} 
exclusivo y privilegiado. Esta experiencia puede transmitirse a través de la compra de un producto, o del uso de un servicio, como lo es el hospedaje.

La definición de lujo ha ido cambiando con el tiempo, es un término que se ve influenciado por factores ambientales, políticos, culturales y religiosos, de forma que el término lujo hoy no solo es un símbolo de sofisticación, como se percibía en el pasado, es un término que ha evolucionado e involucra a un segmento específico del mercado. Para algunos el lujo tiene relación con la clase social, mientras que para otros, el lujo es una experiencia presente en varios sectores de la sociedad a través de la vivencia de experiencias únicas que traducen deseos intangibles a productos y servicios tangibles comercializables.

Estos deseos son el fruto de la fuerte influencia que usuarios y consumidores han tenido a través de las tecnologías de la información y la comunicación (TIC), y de las nuevas expectativas generadas por estos medios hacia la vivencia de experiencias anteriormente no imaginadas y la adquisición de productos innovadores y novedosos. Internet proporciona toda la información de los lugares más exóticos del mundo y de la forma en la cual se pueden adquirir, precios, y alternativas. Entonces el ahorrar tiempo se ha convertido también en lujo, y hace parte de esta experiencia.

La innovación, creación y desarrollo de productos y servicios se han convertido en una herramienta fundamental para poder ser competitivos en este tipo de mercado con altas exigencias. La innovación ha dejado de ser una estrategia para convertirse en una herramienta clave en el desarrollo de una empresa. Debido a la globalización de la información y de los mercados, de acuerdo con Danziger $(2005)^{19}$ se han producido una serie de cambios que han llevado a las marcas de lujo a replantearse su acercamiento a los consumidores:

\footnotetext{
${ }^{19}$ Danzinger, P. (2005). Marketing Luxury to the Masses as well as the classes. Estados Unidos: Dearborn Trade Publishing
} 
1. Del lujo tradicional al nuevo lujo. Hace años el consumidor de lujo buscaba el estatus y prestigio social. Hoy en día esto ha cambiado, lo importante es vivir la experiencia, sentirse único.

2. El lujo ya no es dinero. El consumidor lo que busca es la vivencia, es decir la experiencia que puede estar vinculada a una compra o disfrutar de un servicio, es un estilo de vida, hacer lo que quiere hacer, sentirse feliz.

El mercado de lujo se ha convertido en un mercado de gran interés por lo cual el marketing ha tenido que evolucionar rápidamente. La creación de campañas de productos de lujo, creación de grupos elite, tarjetas de crédito Gold y Premium que permiten acceder a productos exclusivos, asistir a eventos únicos, viajes a lugares exóticos, entre otros, motiva a los usuarios a pagar por vivir estas experiencias, y obtener los privilegios y beneficios. El lujo parece tener niveles, ya que los consumidores una vez alcanzan uno quieren avanzar al siguiente, convirtiendo esta práctica en una necesidad en vez de un placer como lo era hace algunos años.

\subsubsection{Clasificación del lujo}

De acuerdo con Campuzano (2005) ${ }^{20}$ el lujo puede clasificarse teniendo en cuenta diferentes criterios como se indica a continuación:

Según el confort: esta clasificación muestra como hoy en día es más valiosa la comodidad y la tranquilidad como parte de esa vivencia de lujo.

${ }^{20}$ Ibid Campuzano. (2003) 
Según el criterio de la accesibilidad al bien, es decir en la capacidad económica de adquirirlo diferenciamos tres tipos: el lujo inaccesible, el lujo intermedio y el lujo accesible.

De acuerdo a Martínez (2006) ${ }^{21}$, referirse a lujo de manera concreta significa hacer énfasis en el producto, en la Imagen, en la marca, en el empaque, en la comunicación y la distribución. Son estos mismos factores los que definen el éxito de una campaña de marketing que pretende enviar un mensaje claro, establecer una comunicación con el segmento de lujo y en general con todos aquellos que quieren vivir una experiencia de lujo.

Aunque al hablar de lujo se piense casi instantáneamente en marcas que ofrecen productos, este concepto también hace parte del sector de servicios. Aunque actualmente el uso del lujo no esté totalmente desarrollado en este sector, el potencial es muy alto y su rápido crecimiento en los últimos años lo convierten en un sector interesante para el marketing experimental. De hecho, usando como base el trabajo de Martínez (2006) ${ }^{22}$, es posible plantear una breve descripción de los conceptos del marketing aplicados al sector de lujo a nivel general y direccionado a las empresas de servicios:

1. Servicio: El servicio prestado debe transmitir al usuario la sensación de exclusividad, es algo que pocos pueden vivenciar. La ambientación del lugar debe contener detalles llamativos pero sobrios; en muchas ocasiones son elementos artesanales que además de hacerlos únicos, y de elevar su precio, hacen que el consumidor tenga una sensación de beneficio especial, el despertar el sentido de la exclusividad.

\footnotetext{
${ }^{21}$ Martinez De Cestafe, N. (2006). Documento De Trabajo. El Mercado De La Cosmética De Lujo: La Relación entre la marca y la distribución selectiva en Alemania. Tesina Fin de Carrera del European Business Programme (EBP España) de la Cámara de Comercio e Industria de Madrid. Universidad Antonio de Nebrija y University of Applied Sciences Münster. España.

${ }^{22}$ Ibid Martínez (2006)
} 
Para este sector es fundamental incluir elementos que transmitan confort, colores, aromas, imágenes, y hasta el mobiliario es fundamental para transmitir el mensaje correcto a este sector.

2. Marca: la marca es un factor de gran influencia sobre el comportamiento de consumo, muchas veces los clientes y usuarios se sienten atraídos a un producto o servicio porque la marca es lo suficientemente importante y sofisticada, lo que los lleva a querer vivir la experiencia de hacerlos suyos, es más, en muchas ocasiones es importante hacer pública esta experiencia para sentirse diferente y privilegiado frente a los demás.

Es la confianza que les transmite la marca lo que los eleva a otro nivel social.

3. Precio: El precio está estrechamente vinculado al valor de calidad. Muchas veces la percepción de calidad depende de si un producto o un servicio es bajo o alto. Un precio alto en el caso de un producto denota mayor esfuerzo, mejor calidad en las materias primas, buen desempeño, excelente servicio post venta, y para el caso de un servicio, el precio puede transmitir calidad en el servicio prestado, atención personalizada, atención a las necesidades, entre otras.

La determinación de si un precio es alto o bajo, la evalúa el cliente cuando tiene la posibilidad de comparar, para el sector de lujo, el precio además está relacionado con las expectativas que el usuario tiene del producto o servicio, y en algunas ocasiones con la capacidad de pago del cliente.

4. La comunicación: la comunicación involucra todos estos factores transformándolos en un mensaje claro direccionado a usuarios y consumidores a través de campañas publicitarias adecuadas. 
Los medios elegidos para realizar la comunicación, el mensaje, el tiempo, el material publicitario utilizado, el lugar de lanzamiento, son parte de los detalles que hay que evaluar cuidadosamente para no crear confusión y para incorporar una idea clara de lujo en la mente de quien atiende al mensaje. Algunas campañas de lujo incluyen eventos en lugares exclusivos y costosos, ediciones limitadas, colores dorados, negros, blancos y plateados que denotan sofisticación. 


\title{
CAPITULO ॥
}

2. MARKETING OLFATIVO EN HOTELES DE LUJO

\author{
"Lo que ayer era lujo, no lo es hoy" y lo que es lujo hoy, \\ mañana será una necesidad \\ -Danziger-
}

El sector hotelero de lujo ha logrado un crecimiento en la oferta de servicios que se ha mantenido hasta el 2012 en respuesta a la demanda del mercado. De acuerdo a la información publicada en Top Hotels Projects (2013) ${ }^{23}$, para el 2013 se estima la apertura al público de más de 1500 hoteles de primera clase con 546.700 habitaciones en todo el mundo, 207 hoteles en Asia, con 848 hoteles de lujo en Europa, 451 en Norteamérica, 93 en África, 43 en Sudamérica y 30 en Oceanía, entre otros proyectos en curso.

De acuerdo a la anterior información podría decirse que el sector hotelero es un mercado con perspectivas de crecimiento interesante a nivel global y en particular cuando se habla del segmento de lujo. En consecuencia, y con el ánimo de describir las estrategias de marketing olfativo que allí se usan, se procederá a caracterizar en un primer momento el perfil de los hoteles de lujo y definir los elementos que hacen que un hotel sea catalogado como tal. Posteriormente, se procederá a describir el perfil del huésped de lujo, diferenciando en este proceso los diferentes tipos de huéspedes que puedan existir, para finalmente ver las

\footnotetext{
${ }^{23}$ Top Hotels Projects. Recuperado el 22 de enero de 2013 de http://www.tophotelprojects.com/es/acerca-denosotros.
} 
aplicaciones del marketing olfativo en el sector hotelero de lujo y el impacto de estas estrategias de marketing.

\subsection{El hotel de lujo}

Definir el hotel de lujo no es una tarea sencilla, pese a que existan factores en común en la definición y clasificación del sector hotelero. Sin embargo, algunos autores han emitido su criterio al respecto con el fin de identificar y diferenciar a dicho segmento. De acuerdo con Barrows y Powers $(2009)^{24}$ el hotel de lujo es la categoría más alta en la clasificación por precio, donde se encuentran hoteles que tienen en promedio 150 a 400 habitaciones e incluyen una amplia gama de servicios y amenities ${ }^{25}$. Entre los servicios que ofrece se encuentra una amplia carta de bebidas y comidas, servicio gourmet y buffet, actividades recreativas para todos los gustos, entre otros servicios incluidos.

Como parte de esta tendencia de lujo Donald J. Trump lanzó en el 2007 una línea hotelera de lujo, Trump Hotel Collection, donde el mensaje se enfocaba en la experiencia de viaje ofreciendo un servicio exclusivo. Hacen parte de la cadena el Trump International Hotel \& Tower en Nueva York y el Trump Ocean Club International Hotel \& Tower Panama y Toronto entre otros.

De la misma forma, Barrows \& Powers $(2009)^{26}$ mencionan que existen empresas como Zagat publishes que se dedican a emitir publicaciones sobre restaurantes, hoteles, y otros establecimientos alrededor del mundo y a categorizarlos basados en la calificaciones de más de 20.000 viajeros frecuentes. De acuerdo a la información que los viajeros suministraron referente a sus experiencias, ésta

\footnotetext{
${ }^{24}$ Barrows, C y Powers, T. (2009). Introduction to The Hospitality Industry. New Jersey, Estados Unidos.

${ }^{25}$ Amenities o amenidades: Son artículos de aseo personal que el hotel ofrece de manera gratuita como un servicio para el disfrute del cliente y puede incluir champú, gel de ducha, entre otros. Escobar, Eduardo Felipe. (2011). El Confort como una importante dimensión de Calidad en la hotelería Vol 4, No9. Escuela de Hoteleria y Turismo de Camaguey.

${ }^{26}$ Ibid Barrows y Powers (2009)
} 
empresa hizo la siguiente categorización: cadena hotelera top, mejor hotel, mejor resort, mejor pequeña propiedad y mejor spa.

Al igual que Zagat ${ }^{27}$, existen otras organizaciones (y por tanto criterios de evaluación) que buscan categorizar hoteles y restaurantes de acuerdo al cumplimiento de ciertos requisitos. Estas organizaciones han creado diferentes parámetros considerados como mínimos para que un hotel obtenga el reconocimiento de hotel de lujo, y ser calificado según sea el caso, como hotel de 5 estrellas u hotel AAA dependiendo de la evaluación.

Entre las organizaciones que valoran y categorizan los servicios que los diferentes hoteles ofrecen, se encuentra La Unión Hotelstars ${ }^{28}$. Esta es una organización que califica con estrellas a los diferentes hoteles de los países asociados mediante la unificación de criterios de evaluación, de forma tal, que se les pueda brindar transparencia y seguridad a los huéspedes, asegurando características de confort estándar en cualquier hotel calificado con la misma cantidad de estrellas. De acuerdo al listado de criterios que informan en su página web, en el siguiente cuadro se resume la información de clasificación por estrellas para un hotel 4 y 5 estrellas:

\footnotetext{
${ }^{27}$ Ibid Barrows y Powers (2009).

${ }^{28}$ Criterios de Clasificación de Hoteles. Recuperado el 5 de Febrero de 2013 de http://www.hotelstars.eu/es/index.php?open=Criteria.
} 
Tabla 1 - Parámetros de clasificación de hoteles para cuatro y cinco estrellas.

\begin{tabular}{|l|c|}
\hline & $X$ \\
\hline $\begin{array}{l}\text { - Servicio de recepción las } 24 \text { horas con personal } \\
\text { multilingüe }\end{array}$ & $\mathrm{X}$ \\
\hline $\begin{array}{l}\text { - Mini-bar, 24 horas de servicio de comida y bebidas } \\
\text { mediante servicio de habitaciones }\end{array}$ & $\mathrm{X}$ \\
\hline - Servicio de portería o estacionamiento. & $\mathrm{X}$ \\
\hline $\begin{array}{l}\text { - Hall de entrada espacioso con varios asientos y } \\
\text { servicio de bebidas }\end{array}$ & $\mathrm{X}$ \\
\hline - Conserje, botones & $\mathrm{X}$ \\
\hline $\begin{array}{l}\text { - Saludo personal de bienvenida a cada huésped con } \\
\text { flores frescas o regalo en la habitación }\end{array}$ & $\mathrm{X}$ \\
\hline - Productos de cuidado personal en frascos & $\mathrm{X}$ \\
\hline - Ordenador con acceso a internet en la habitación & $\mathrm{X}$ \\
\hline$\bullet$ Caja de seguridad en la habitación & $\mathrm{X}$ \\
\hline $\begin{array}{l}\text { - Servicio de plancha (con devolución en una hora), } \\
\text { servicio de limpieza de zapatos }\end{array}$ & $\mathrm{X}$ \\
\hline
\end{tabular}

Fuente: Adaptado de Criterios de Clasificación de Hoteles. ${ }^{29}$

Para realizar la evaluación, Hotelstars toma una tabla preestablecida y califica una serie de parámetros como: limpieza e higiene, condición general, impresión general, recepción, habitaciones, área publica, facilidades para personas discapacitadas, estacionamiento, comodidad en el baño y la habitación, facilidad de depósito, control de ruido/aire acondicionado, entretenimiento, telecomunicaciones, limpieza de la habitación, bebidas, desayuno, comida, lavado y planchado, pagos, spa/belleza y tecnología y otros servicios. Al finalizar la evaluación, se le otorga un puntaje total y tras un análisis de los resultados, se clasifica con el número de estrellas correspondiente.

Siguiendo con los aportes de Barrows \& Powers (2009) ${ }^{30}$, los autores mencionan que en el Reino Unido, Automobile Association, Royal Auto Club y el Consejo Inglés de turismo han adoptado un sistema estandarizado de calificación para sus miembros, que incluye la escala de cinco estrellas donde cinco es considerado el mejor. La calificación incluye, limpieza, servicio, hospitalidad, habitaciones, baños,

\footnotetext{
${ }^{29}$ Criterios de Clasificación de Hoteles. Recuperado el 5 de Febrero de 2013 de http://www.hotelstars .eu/es/index.php?open=Criteria

${ }^{30} \mathrm{lbid}$ Barrows y Powers, (2009). Introduction to The Hospitality Industry. New Jersey, Estados Unidos.
} 
calidad en la comida y en el servicio, seguridad, apariencia exterior e interior. En Alemania y para algunos países escandinavos el sistema válido es el de una a cinco estrellas, las cuales pueden ser otorgadas hasta por tres años antes de que el gobierno realice alguna inspección.

Por otra parte, en Francia, el ministerio de turismo amplio la escala a cinco estrellas, mediante la evaluación y certificación dada por el Comité Francés de Certificación (COFRAC). La firma privada de auditoria estableció la nueva escala con el fin de mejorar la calidad de sus hoteles y ser más competitivos frente al mercado global. Para ello se realiza una evaluación de acuerdo con 246 criterios agrupados en las categorías: equipos (wifi, multimedia, etc.), servicio al cliente, accesibilidad para personas con discapacidad y sustentabilidad (uso de bombillas ahorradoras, uso de productos eco amigables, etc.). Entre los puntos más relevantes de esta clasificación se pueden encontrar para el hotel más lujoso la siguiente descripción:

- 4 y 5 Estrellas -Haut de gamme: Los hoteles de esta alta categoría deben contar con habitaciones sencillas de mínimo $20 \mathrm{~m} 2$ de área y de $24 \mathrm{~m} 2$ para las habitaciones de acomodación doble. Debe contar con elementos de higiene y aseo personal. Debe disponer de $90 \mathrm{~m} 2$ de áreas comunes disponibles como mínimo. Los hoteles con más de 2 niveles deben contar con acceso a elevador. El personal debe hablar inglés y como mínimo dos idiomas extranjeros

Aunque el sistema de calificación más común es el de estrellas, no es el único sistema de calificación. Para algunos tener 4 o 5 estrellas no es suficiente para calificar a un hotel como un hotel de lujo. Para estar dentro de esta prestigiosa categoría según la AAA (American Automobile Association) es importante hacer un seguimiento estricto en los diferentes factores y servicios que el hotel ofrece para poder ser calificado con esta alta puntuación. 
La AAA ha hecho estudios y otorgado calificaciones a aproximadamente 32.000 hoteles en Estados Unidos, Canadá, México y el caribe, además de ser parte de la calificación en países como el Reino Unido. Esta evaluación incluye factores como limpieza, comodidad, seguridad, además de los servicios, los amenities y la decoración, las calificaciones van desde la más sencilla hasta la más lujosa, en una escala de diamantes de uno a cinco. Sin embargo pese a ser muchas las propiedades evaluadas año a año, menos del uno por ciento obtiene la máxima calificación de cinco diamantes. Esta asociación además de evaluar hoteles, también evalúa restaurantes, atracciones y eventos con altos estándares de calificación. Hoteles como los de la cadena Kimpton ${ }^{31}$, se encuentran dentro de este privilegiado listado ofreciendo a sus huéspedes alternativas como conocer al chef, servicios completos de spa, servicios para mascotas e incluso alternativas para eventos en mercados definidos como la comunidad de lesbianas, gais, bisexuales y transexuales (LGBT).

A continuación una breve descripción de la categorización cuatro y cinco diamantes como la más exclusiva con los estándares más altos:

- Cuatro y cinco Diamantes: Estos establecimientos reflejan las características de lo último en lujo y sofisticación. Acomodación de primera clase. Los atributos físicos son extraordinarios en todos los aspectos. Los factores más importantes en este nivel son la preocupación por el servicio y por cumplir y sobrepasar las expectativas de sus huéspedes manteniendo los estándares de la excelencia. Muchos de los servicios y amenities transmiten incomparables niveles de confort. Los restaurantes de este hotel ofrece una experiencia de primera clase. Spas y zonas de descanso, además de actividades deportivas entre otras.

El sector de lujo en hotelería podría identificarse por la calificación y evaluación realizada, sin embargo, otros criterios como el target objetivo son considerados

\footnotetext{
${ }^{31}$ Kimpton Hotels \& Restaurants. Recuperado de https://www.kimptonhotels.com/. (2013)
} 
importantes, de manera que los hoteles se podrían categorizar de acuerdo a su infraestructura y target objetivo de la siguiente forma:

- Hoteles de Cadena: Son hoteles con marcas que rompen las fronteras de un país o ciudad creando una línea de hoteles que mediante imágenes, logos y estándares de servicio intentan transmitir el mismo mensaje en diferentes lugares del mundo, y de esta manera ser identificados y reconocidos, tal es el caso de la línea de hoteles Sheraton, Marriot y Hilton entre otros, que cuentan generalmente con grandes predios y variedad en la oferta de espacios y habitaciones, entre las cuales se encuentran las lujosas suites que cuentan con servicios especiales y algunos exclusivos para los visitantes de estos.

- Hoteles boutique: Son pequeños hoteles, que muchas veces tienen entre su oferta habitaciones con diseños únicos y diferentes de las otras, son espacios pequeños, pero cálidos y con una amplia gama de servicios que incluyen días de spa, masajes en la habitación, y servicio a la habitación las 24 horas. Uno de los elementos más representativos de este tipo de hoteles es que por su tamaño, permiten atención casi personalizada, lo cual agrega un valor al huésped. La utilización de detalles de diseño transmite exclusividad. El target objetivo de este tipo de hoteles va direccionado a huéspedes sofisticados que buscan vivir una experiencia de hospedaje diferente.

Los primeros hoteles boutique surgieron en Nueva York, San Francisco y Londres por los años 80, el primer hotel de diseño en Buenos Aires fue el Design Suites que se inauguró en 1999. Hoy en día existen muchos hoteles en esta categoría de hoteles boutique de diseño. El Duque Hotel Boutique, el Blue Soho Boutique Hotel en Buenos Aires Argentina y el Anandá Hotel Boutique en Cartagena Colombia son ejemplo de estos.

- Hoteles temáticos: Son aquellos que pretenden despertar en el huésped la sensación de exclusividad al ofrecer habitaciones diferentes donde 
generalmente la decoración es un elemento que transmite sofisticación y exclusividad para que el huésped sienta que solo él puede experimentar la experiencia de estar en ese lugar. Muchos de estos hoteles van dirigidos a grupos culturales específicos y otros simplemente intentan posicionarse como una alternativa diferente, es el caso de los hoteles que imponen en su decoración muchos elementos de arte, como los ubicados en San Telmo en Buenos Aires, donde muchos artistas aprovechan para difundir su música, danza y sus obras. Ejemplo de este tipo de hoteles es el hotel del Boca en Buenos Aires, un hotel temático cinco estrellas dedicado al futbol perteneciente a la cadena de hoteles Design Suites.

- Hoteles ecológicos o verdes: Con la puesta en moda de las tendencias en busca de la protección del medio ambiente y la naturaleza, se han creado este tipo de hoteles que mediante la utilización de recursos renovables, y naturales buscan generar en el huésped la sensación ambientalista, de cuidado con la naturaleza como un aporte al cuidado del medio ambiente y la prolongación de la vida. Es una tendencia en crecimiento en la que se destacan hoteles lujosos como el Crowne Plaza Copenhague Towers en Dinamarca donde ofrecen menús ecológicos y cuentan con sistemas de ahorro energético, con el uso de paneles solares, sistemas de aguas subterráneas, generación de energía proveniente del pedaleo de bicicletas estáticas en el gimnasio, uso de electrodomésticos de bajo consumo, etc. Otros prestigiosos hoteles que siguen estas políticas ambientales son el hotel Scandic Hasselbacken de Estocolmo y el Carlton hotel Guldsmeden en Copenhague. Además existen proyectos como el Aerohotel en Dubai y el hotel Bardessono en California que proponen alternativas verdes. De esta manera se podría decir que es una de las categorías en mayor desarrollo dentro de la línea hotelera.

Otros hoteles tienen targets objetivo específicos, como el caso del hotel Axel Hotel Barcelona, un hotel dirigido a la comunidad gay, aunque cualquier persona puede acceder a este tipo de hoteles, su temática está claramente definida sin perder el glamour y el diseño. 
Son diversos los factores que se ven involucrados en la creación de nuevos espacios, la tecnología es uno de los que mayor influencia tiene en el diseño de los hoteles de lujo. Actualmente la tecnología incorpora herramientas que facilitan al huésped su estancia, amplios espacios en la habitación con controles digitales para seleccionar no solo un programa de televisión, sino la música, la intensidad de las luces, la dureza del colchón, y el menú entre otras. Inclusive existen hoteles inteligentes que transmiten mediante la utilización de modernas herramientas de comunicación, confort y seguridad.

Siguiendo con lo anterior, también es importante tener en cuenta los siguientes factores como elementos involucrados en la creación de espacios de lujo:

- Ubicación: No existe una ubicación determinada para catalogar a un hotel de lujo, sin embargo muchos de ellos están localizados en sectores exclusivos, algunos apartados, con paisajes exóticos y con poca gente, donde puedan disfrutar de una experiencia que preferirían fuera única.

- Vista: Generalmente las suites más costosas de los hoteles de lujo, son aquellas que tienen vista panorámica a las afueras, muchas con vista al mar, a las montañas, a la ciudad, a los paisajes más representativos del lugar. Hoteles diseñados pensando en el huésped que quiere admirar el exterior, con grandes ventanales, con balcones y terrazas que permiten admirar estos lugares e incluso amoblados con elementos que permiten a los visitantes disfrutar de una tarde de sol desde la habitación, o tener una cena romántica en la terraza con vistas maravillosas.

- Comodidad: Generalmente los huéspedes que visitan este tipo de lugares desean tener una experiencia de relax, y por ello prestan atención a detalles como la calidad de las sabanas, almohadas y cobijas del cuarto, a la comodidad de la cama y el baño. Cuando se habla de comodidad en el sector hotelero, se asocia en primera instancia con la habitación, sin 
embargo, es un término que viene asociado a todos los ambientes del hotel, facilidades para asistir a las otras zonas, y facilidad para obtener los beneficios que ofrece el lugar sin tener que hacer mucho esfuerzo tal es el caso de hoteles que ofrecen atención personalizada, cena en el cuarto, entre otras.

- Espacios: Amplios cuartos, suites privadas que incluyen todos los servicios, zonas de recreación y descanso son un factor común para los hoteles de lujo, muchos de estos espacios se encuentran aromatizados para complementar esta experiencia a través de los sentidos, aromas relajantes en las zonas de spa, recepción y en algunas de las habitaciones.

- Servicios: hoteles como el Tadrai Island Resort en la isla Mana ofrecen entre su plan all inclusive servicios como chef privado en la habitación comedor, cocktails en las cabañas a la orilla del mar. El Hotel Burj al Arab 7 en Dubai ofrece a sus huéspedes un servicio de desplazamientos en Rolls Royse Silver Seraph.

Entre los servicios que ofrecen este tipo de hoteles se encuentran, la atención 24 horas, centros deportivos, y de spa, piscinas, wifi, una zona de recepción en la habitación, servicio de empacar y desempacar, lavandería, servicio de café en el lobby, servicio de llamadas locales e internacionales, incluso hay algunos que tienen servicio de helipuerto.

- Actividades: La exclusividad del hotel de lujo no solo se sitúa en sus espacios, es precisamente la experiencia el factor más importante, por lo cual ofrece a sus huéspedes una amplia gama de actividades que incluyen, relax, descanso, así como también deportes extremos, buceo, snorkle, surf, golf, spa, excursiones y visitas exclusivas. Es el recuerdo de esa experiencia única, la imagen del hotel que permitió vivenciar esto, lo que se traduce en un lujo. 
Para el presente trabajo, de acuerdo a lo citado anteriormente, definiremos al hotel del lujo como aquel hotel que cumpla con los parámetros más exigentes de clasificación en las diferentes escalas de evaluación, siendo para la unión Hotels stars cuatro y cinco estrellas y para la AAA cuatro y cinco diamantes. Condiciones que pueden cumplir diferentes tipos de hotel (boutique, cadena, etc.).

\subsection{El huésped de lujo}

Con el fin de abordar las estrategias de marketing utilizadas en el sector hotelero, es necesario identificar el perfil del usuario de este tipo de servicio, a quien será llamado en el presente trabajo "el huésped de lujo".

Como se ha dicho hasta el momento, la experiencia que pueda tener un cliente del sector hotelero representa un factor primordial a la hora de seleccionar el hospedaje. Es por ello, que los hoteles de lujo se esfuerzan por incluir no solo amplias habitaciones sino por brindar a través de la distribución de los espacios, los servicios prestados, los colores utilizados y los olores seleccionados, una sensación de confort que transmita la identidad de la marca del hotel. Para lograrlo, los hoteles deben intentar definir el perfil del huésped de lujo, dando respuesta a algunas preguntas relativas a cuestiones como: ¿Quién es el huésped de lujo? ¿Qué espera encontrar en un hotel de lujo? ¿Cuánto está dispuesto a pagar?

Al respecto de la primera pregunta, es importante decir que no es fácil definir al huésped de lujo debido a que no existe una categorización definida, un perfil claro por género, por edad, por raza o religión. Sin embargo, de acuerdo a los elevados precios que hay que pagar y a los servicios que ofrecen los hoteles de lujo (como el Mandarin Oriental en Nueva York cuya tarifa supera los 500 dólares por noche), parece que existe cierta condición económica - social característica del huésped 
de lujo. No todas las personas pueden y/o están dispuestas a pagar las elevadas tarifas que ofrecen éste tipo de hoteles. Muchos de los usuarios de lujo son el resultado de la experiencia vivida en varios de estos lugares, donde la comparación es un elemento fundamental que les lleva a ser cada vez más exigentes a la hora de seleccionar el siguiente destino.

Sería posible clasificar al huésped de lujo, usando a manera de criterio, la clasificación de los servicios ofertados por la mayoría de los hoteles de la siguiente forma:

- El ejecutivo o viajero de negocios: es aquel que frecuenta este tipo de establecimientos por motivos de negocios, visitas de trabajo, capacitaciones, entre otras. Son personas con altas exigencias, buscan descanso después de las agotadoras jornadas de trabajo, y requieren de servicios de tecnología que faciliten la comunicación y su visita.

Generalmente son individuos que tienen la cultura de viajar por lo cual algunos de ellos tienen tarjetas platinum y goldque les permite acceder a otros beneficios en los diferentes hoteles asociados y los lugares que visitan. Esta podría considerarse una de las estrategias de fidelización que utilizan algunos hoteles, tal es el caso del Starwood Preferred Guest (SPG), un plan que ofrece una subscripción mediante la cual se le permite a los usuarios acceder a hoteles de lujo alrededor del mundo, sumar puntos y obtener beneficios como noches de alojamiento de cortesía en hoteles de alta categoría. Este tipo de huésped generalmente visita hoteles de cadena, que están estratégicamente ubicados y cuentan con las facilidades que permiten a los huéspedes cumplir con el objeto de su visita.

- El Solitario: Es aquel que visita este tipo de lugares buscando salir de la rutina. Quiere beneficios extra en el establecimiento que le permitan sentirse diferente. Algunos quieren descanso y otros son más osados y buscan vivir experiencias de aventura donde puedan experimentar el 
contacto con la naturaleza, ver paisajes inimaginables, conocer otras culturas, y hasta estar en contacto con otras especies vegetales y animales en su hábitat natural. Es importante para este tipo de huésped contar con servicios de transporte, algunos realizan exigencias en el menú, planes turísticos, vista a paisajes exóticos, equipamiento de aventura, entre otros.

- El viajero familiar: Aquellos que viajan en grupo familiar y buscan conocer un lugar diferente, prefieren asistir a hoteles que les ofrezcan todas las facilidades de transporte, alimentación y actividades para todos, de manera que no tengan que realizar mayor esfuerzo al de pagar para cumplir con sus expectativas. Este tipo de huéspedes requieren de ciertos elementos que les permitan tener una experiencia en familia sin inconvenientes, algunos solicitan servicio de guardería, lavado de ropa, y agencia de turismo familiar.

- El turista en pareja: Muchos gustan de viajar y a la hora de elegir prefieren hacerlo en compañía de alguien y quien mejor que su pareja, amigo o amiga de viaje. Este tipo de huéspedes gustan de hoteles que tengan planes turísticos diferenciales, muchas veces los hoteles boutique son la mejor elección, ya que muchos de ellos ofrecen cuartos privados equipados para dos, y en el caso de los viajantes en plan romántico, éstos hoteles junto con los de cadena tienen planes diseñados para pasar una velada única y exclusiva en el destino elegido.

Al respecto de la segunda pregunta, ¿Qué espera encontrar en un hotel de lujo?, Si nos ubicamos en el hotel de lujo y tratamos de listar los servicios y amenities que el huésped de lujo espera encontrar en el hotel que visita, se podría decir que no existe una respuesta general a dicha cuestión, dependiendo del perfil del huésped de lujo, de la actividad que realiza y de los motivos que lo han llevado a visitar este lugar, la respuesta puede ser única de acuerdo a las necesidades individuales. 
En consecuencia, los hoteles de esta categoría hacen un gran esfuerzo por ofrecer a sus huéspedes servicios y actividades que puedan representar un factor diferencial frente a la gran demanda hotelera.

Hoteles como el Ritz-Carlton en Montreal, calificado con cinco diamantes, ofrece no solo espacios amplios, lujosos y elegantes sino que lo acompaña de actividades y servicios que transmiten confort, exclusividad y glamour. Elementos como chimenea, mesas de reuniones, y objetos de diseño en la habitación, además de contar con paquetes de organización de eventos y boutique.

Otros viajeros de lujo optan por un plan tranquilo donde el descanso y el confort son dos elementos fundamentales; quieren disfrutar de la playa y de una atención que les permita tener una experiencia individual y de primera clase sin perderse de la vista panorámica de los paisajes exóticos que ofrezca el lugar; tal es el caso del Rosewood Mayakoba en Playa del Carmen México, otro hotel calificado con cinco diamantes que dispone de hermosos paisajes y servicios exclusivos a disposición de sus huéspedes, atención personalizada, servicio a la habitación, spa y masajes, entre otros.

El huésped de lujo busca un hotel de acuerdo a sus expectativas individuales, pensando en cumplir con su objetivo: trabajar, descansar, conocer, o simplemente pasar unos días fuera, y para ello quiere hacer el menor esfuerzo posible. Es por ello que la facilidad en la adquisición de información turística del lugar, acceso tecnológico como internet, wifi, teléfono, facilidad para reservar y rapidez en la atención al momento de realizar check in y check out se han convertido en otra herramienta para atraer a estos codiciados huéspedes.

Muchos de estos servicios se encuentran en hoteles de todas las categorías, es por ello que los hoteles de lujo recurren a otro tipo de estrategias de marketing que permitan marcar diferenciación. Es allí, donde el marketing experimental se convierte en una herramienta que facilita alcanzar el objetivo de convertir la visita 
en una experiencia positiva e inolvidable. Los paisajes, los colores del lugar y los aromas son parte fundamental en esta tarea, tal es el caso del Hotel Burj Al Arab en Dubai donde el lujo y el confort son el mensaje claro que transmiten cada uno de los espacios diseñados para vivir el lujo.

Para terminar con los cuestionamientos mencionados al comienzo del presente capítulo, cuando nos preguntamos ¿Cuánto está dispuesto a pagar el huésped de lujo?, podríamos decir que en general el precio no es un factor restrictivo para el exigente huésped de lujo, es más, tener la oportunidad de disfrutar de las hermosas playas de Tailandia, la modernidad de Las Vegas, el romanticismo de Paris, la oferta gastronómica de South Beach en Miami y la exclusividad de lugares como Gstaad en Suiza, las playas de Tailandia, y la magia de la glamurosa Venecia, es un lujo al que no todos pueden acceder donde el precio no es una limitante a la hora de elegir.

Cada uno de los elementos involucrados al transmitir el mensaje de lujo hacen parte del precio, el cual se ha convertido en un factor diferenciador en el sector hotelero; donde los elevados precios definen en muchos casos el perfil del huésped que tiene la capacidad económica de pagarlos y sobre todo para quien la experiencia se ha convertido en el principal motivo dejando de lado los otros aspectos.

En conclusión no hay un precio establecido, éste depende del lugar, de los servicios ofrecidos y claro está, de lo que el codiciado huésped esté dispuesto a pagar, sin embargo el precio se ha convertido en muchos casos el factor diferencial. 
2.3 Aplicaciones del marketing olfativo a hoteles de lujo. Del marketing en almacenes de retail a hoteles.

En la actualidad el marketing olfativo ha sido implementado en algunos supermercados, restaurantes, tiendas de cadena, centros comerciales y en general en los establecimientos donde el cliente tiene que estar en contacto con el servicio o producto para su compra o recompra.

Cada vez son más los almacenes de Retai $^{\beta 2}$ que utilizan fragancias en sus locales mediante diferentes técnicas de ambientación como spray, difusores de bambú, ambientadores textiles, difusión mediante el aire acondicionado y con sistemas eléctricos, para generar un ambiente agradable que tenga un impacto positivo. La utilización de estas técnicas tiene alguno o algunos de los siguientes objetivos:

- Promover la estadía de sus clientes en las tiendas y así mismo generar un aumento de las ventas.

- Generar recordación y fidelización entre sus cliente, mediante la utilización de estímulos a través de la incorporación de aromas que influyen en el comportamiento de los consumidores.

Al igual que algunos almacenes de marcas de lujo, los hoteles de lujo quieren transmitir lujo y sofisticación a través de la decoración de sus espacios, además intentan crear una identidad que les permita ser recordados, tal como ocurre con el Hotel Venetian en Las Vegas que tras 3 años de construcción para la apertura de la primera etapa del complejo, el glamuroso hotel intenta representar a Venecia, adhiriéndose así a otros hoteles cuyas construcciones nos trasladan a exóticos lugares y maravillas del mundo.

\footnotetext{
${ }^{32}$ Retail: Refiere a la venta de bienes en pequeñas cantidades al consumidor o usuario generalmente en un punto de venta fijo. Sandilands, Tracey. Small business. Definition of Retail Marketing. Recuperado de http://smallbusiness.chron.com/definition-retail-marketing-40196.html . 2013.
} 
La primera impresión de los usuarios en un establecimiento comercial está dada por la percepción del diseño exterior e interior, donde se ven involucrados el color, la iluminación, la decoración, es decir influencia en primer momento al sentido de la vista. Pero la percepción del aroma no es menor, puede impactar de primer momento e influir en el tiempo de permanencia del individuo en el lugar y en la intención de compra. De acuerdo con Gómez y García (2010) ${ }^{33}$, así como los colores tienen influencia en las reacciones emocionales de los consumidores, los olores tienen un gran impacto en el comportamiento de los mismos, igualmente Davies, Kooiman, y Ward, (2003) ${ }^{34}$ menciona el importante nivel de evocación y recordación por parte del sistema nervioso a los estímulos olfativos que conectan con áreas del cerebro que están relacionados con los recuerdos, acción que facilita la evocación y fidelización de clientes y usuarios. El sentido del olfato es tan importante que organizaciones como The Olfactory Research Fund, se dedica a la investigación y patrocinio de proyectos relacionados con la influencia de los olores y las fragancias en las percepciones

Cuando se habla de utilización de fragancias en establecimientos comerciales deben tenerse en cuenta variables como: la intensidad del olor (fuerte o débil), el carácter del aroma (nota olfativa) y el impacto del mismo. El aroma pretende transmitir la identidad del lugar, por lo cual el mismo debe ser generado por el ambiente del establecimiento, o estar relacionado al mismo. Muchas veces se utilizan fragancias en lugares donde es muy difícil que los productos que se comercializan en el mismo sean los responsables del mismo, es allí donde las casas de fragancias dedicadas al diseño y comercialización de los aromas han puesto sus esfuerzos en diseñar fragancias que estén en línea con los valores que la empresa quiere transmitir. Para ello involucran factores como el target objetivo, los valores de la empresa, los colores corporativos y hasta el logotipo de la

\footnotetext{
${ }^{33}$ Gómez, M. y García, C. (2010). "Nuevas tendencias en el punto de venta: el marketing sensorial", Distribución comercial y comportamiento del consumidor", Cátedra Fundación Ramón Areces de Distribución Comercial, Universidad de Oviedo

${ }^{34}$ Davies, B. J., Kooiman, D. and Ward, P. (2003), "The Sweet Smell of Success: Olfaction in Retailing”, Journal of Marketing Management, Vol. 19 Issue 5/6 (July), 611-627
} 
empresa con el ánimo de crear un aroma que este alineado con toda esta información de forma coherente.

De acuerdo con Sherman (1997) ${ }^{35}$ las personas pueden tener diferentes reacciones a la hora de visitar un punto de venta, las cuales se ven influenciadas por el estado de ánimo que experimenta el individuo, por ejemplo, cuando una persona experimenta hambre puede ser susceptible de realizar compras compulsivas. Es importante tener en cuenta que estos antecedentes pueden servir de base para aplicar estos estímulos a otros ámbitos que no sean puntos de venta, como es el caso de un hotel, donde el huésped paga por un servicio, por vivir una experiencia de bienestar, un intangible.

Si se aplican las técnicas de marketing olfativo a los hoteles de lujo, los resultados podrían sorprender a muchos, es más, actualmente muchos de los hoteles de cadena y más aún los hoteles boutique ya utilizan fragancias en espacios comunes como la recepción y los baños, sin embargo, generalmente las fragancias utilizadas para ambientar este tipo de hoteles son fragancias genéricas como vainilla y naranja sin tener en cuenta que la elección de las mismas debe estar alineada con los objetivos y valores corporativos, lo cual rompe en cierta medida con el proceso de relación olor - marca; que constituye un pilar para el marketing experimental, perdiendo la posibilidad de generar recordación de marca y obtener respuestas positivas por parte de los huéspedes reflejadas en fidelización y aumento de ventas.

Esta necesidad ya ha sido detectada por algunas empresas de marketing olfativo dedicadas a comercializar fragancias y sistemas de difusión de aromas, las cuales intentan darle a la marca un valor agregado a través del sentido del olfato, como el caso de Scentair la empresa que aromatiza la cadena de hoteles Westin, The Cosmopolitan en Las Vegas y el Aria en Las Vegas, entre otros. Ésta al igual que

\footnotetext{
${ }^{35}$ Sherman, E., Marthur A. y Belk S.R. (1997), "Store environment and consumer purchase behavior: mediating role of consumer emotions”, Psychology \& Marketing. Wiley Periodicals, Inc., A Wiley Company
} 
otras empresas se ha enfocado en el desarrollo de fragancias para este tipo de servicios como el sector hotelero, el sector retail, e incluso hospitales, con el objeto de crear una reacción positiva por parte de los visitantes. Se podría decir que el marketing olfativo hace parte de la estrategia de venta y fidelización, principalmente de establecimientos de comercialización de ropa y en la prestación de servicios en el área hotelera; sin embargo muchos hoteles, en particular aquellos enfocados al sector del lujo, podrían incluir éste tipo de técnicas para obtener beneficios a corto, mediano y largo plazo, podrían inclusive, crear una marca que los identifique, el llamado odotipo del hotel de lujo para el presente trabajo.

Cuando un hotel de lujo toma la decisión de incorporar un aroma dentro de sus instalaciones tiene dos caminos a nivel general: el primero es tomar un aroma genérico que le permita generar impacto sobre las ventas y una calificación positiva. El segundo camino, el más costoso y arriesgado, pero al mismo tiempo el de mayor beneficio es generar un aroma único, un odotipo del hotel de lujo, el cual podría tener los beneficios anteriormente mencionados en el primer camino y además posicionarse como marca olfativa, ser reconocido por su aroma y transmitir el mensaje de sofisticación y exclusividad. Esto último podría potenciar los otros beneficios y crear una identidad organizacional que puede trasladarse y reproducirse como el caso de los hoteles de cadena que intentan mantener una imagen.

Sin embargo, no es posible decir cuál de las dos alternativas es la más adecuada, ya que esto depende del tipo de hotel, de sus objetivos, misión y visión, de su presupuesto y de la infraestructura del mismo, entre otros factores, lo importante es que sea cual sea el camino elegido, la fragancia debe ser un aroma que identifique y esté relacionado con el mensaje que el hotel quiere transmitir a través de los otros sentidos, incluyendo los colores, el mobiliario, los servicios ofrecidos y por su puesto los valores corporativos. 
CAPITULO III

\section{CREACION DE IDENTIDAD DEL HOTEL DE LUJO A TRAVÉS DEL MARKETING OLFATIVO.}

"Es importante que las compañías analicen, seduzcan y conquisten las emociones y sentimientos de los clientes, creando experiencias tangibles y positivas".

- Harold Torrez M -

El desarrollo de una marca olfativa, también llamada odotipo, implica una serie de pasos que pretenden servir de herramienta para llevar al usuario de manera clara el mensaje que se quiere transmitir, y lo más importante, lograr que se convierta en parte de la experiencia del huésped y que sirva como elemento de recordación y asociación a la marca.

Como se ha mencionado a lo largo del presente trabajo, actualmente el marketing utiliza expresiones como marca olfativa y marketing olfativo para referirse al ámbito en el cual se utilizan fragancias para estimular el sentido del olfato y generar un impacto en quienes lo perciben. En este capítulo se hará un recorrido por el proceso de desarrollo de un logotipo o marca olfativa se sugerirá un modelo de acuerdo a la información citada en los anteriores capítulos referente a la clasificación de los hoteles y huéspedes de lujo, a las publicaciones de Kerzner 
$(2013)^{36}$ y Meredith $(2012)^{37}$ sobre la estructura de un proyecto, a las etapas de desarrollo de un brief de Marketing de acuerdo a Rodriguez $(2013)^{38}$, al proceso de desarrollo de un proyecto sensorial propuesta por Kemp, Hollowood y Hort $(2011)^{39}$ y la experiencia laboral de la autora del presente trabajo en la industria de las fragancias.

De esta forma se expondrá el desarrollo de la marca olfativa en el hotel de lujo y se describirán cada una de las etapas resultantes de la unificación de los procesos de desarrollo de un proyecto, que para el presente trabajo se indicará como un proyecto de desarrollo de aroma para un hotel de lujo. Se citarán algunos ejemplos y sugerencias en cada una de las etapas a modo ilustrativo.

En este proceso intervienen dos partes al igual que en un proceso de venta: el cliente o usuario, para este caso el hotel de lujo, y el proveedor del producto o servicio, al cual llamaremos el desarrollador de la marca olfativa (fragancia $u$ aroma para el presente trabajo). El desarrollador de la marca es quien tiene la experiencia y conocimiento suficiente para asesorar a la otra parte en la selección de la fragancia adecuada.

El proceso consta básicamente de cinco etapas que se describirán a lo largo del presente capítulo:

1. El inicio del proyecto

2. La planeación y los objetivos

3. La estrategia de implementación

4. Ejecución del proyecto, el seguimiento, el método de evaluación y el análisis de datos.

5. Quinta etapa de finalización y cierre

\footnotetext{
${ }^{36}$ Kerzner, H. (2013). Projectmanagement: A systems approach to planning, Scheduling, and controlling . Séptima edicion. Nueva York: Publicado por John Wiley \& Sons.

${ }^{37}$ Meredith, J.R y Mantel S. (2012). Project ManagementA Managerial Approach. Nueva York: Publicado por John Wiley \& Sons. pp 24

${ }^{38}$ Rodríguez, R. (2003). Definición De Investigación De Mercados. Marketing E Investigación De Mercado $2^{a}$ Parte. Recuperado de http://www.gestiopolis.com/canales/demarketing/articulos/68/mktinv2.htm

${ }^{39}$ Kemp, S E., Hollowood, Ty Hort J. (2011). Sensory Evaluation. A Practical Handbook. Wiley Blackwell.
} 


\subsection{Primera etapa, el inicio del proyecto}

En esta primera etapa se debe hacer un análisis general para poder evaluar el contexto en el que se encuentra inmerso el hotel, esto se puede hacer mediante recolección de información que incluye: el nombre del hotel, su logo, la historia, su ubicación geográfica, el clima, entre otros. Vale la pena mencionar que entre más información se obtenga mejor va a ser el acercamiento entre la fragancia seleccionada y la marca.

Esta etapa también incluye el alcance, la determinación de los límites y la evaluación de los beneficios y riesgos que implica la implementación de un aroma como estrategia de marketing dentro del hotel de lujo.

También incluye la definición del mercado objetivo y los segmentos que lo componen, los atributos del concepto que se desea transmitir, la población que lo frecuenta, la cultura en la que se encuentra inmerso, la elaboración del perfil del huésped de lujo del hotel en particular, sus hábitos de consumo y estilos de vida también son parte clave en esta etapa del proyecto, ya que es el punto de partida para todas las etapas que lo seguirán. Un buen inicio conducirá un proyecto exitoso, de lo contrario pueden encontrarse algunos inconvenientes durante las etapas que le siguen.

Un factor que muchas veces no se tiene en cuenta pero que resulta importante en este tipo de proyectos, es el clima, cuando se trata de desarrollar una fragancia para ambientar un espacio en particular hay que tener en cuenta que la temperatura se convertirá en un elemento que puede jugar a favor o en contra dependiendo de la composición de la fragancia. Fragancias cítricas en ambientes muy cálidos tendrán periodos de duración mucho más cortos que aquellas que tienen notas olfativas más dulces, amaderadas y florales. 
No es igual tener un hotel situado en la playa, con clima cálido, donde los servicios ofrecidos están focalizados en ofrecer diversión, comodidad y descanso, que un hotel situado en el centro de una ciudad rodeada de autos y edificios, que está pensado en hombres de negocios con amenities que se centran en satisfacer las necesidades de este tipo de huéspedes.

Otros factores que también deben tenerse en cuenta son la cultura del lugar debido a que cada país, ciudad y hasta comunidad tiene preferencias diferentes; algunos se inclinan por los aromas dulces, mientras que otros prefieren los florales o amaderados, incluso el uso de algunas fragancias por tradición influye en la percepción del visitante.

Es por ello que podríamos decir que, cada detalle se presenta como un factor importante ya que permitirá al desarrollador de la fragancia, tener más herramientas para diseñar o seleccionar la fragancia más adecuada de acuerdo al concepto que la marca pretende transmitir.

\subsection{Segunda etapa, la planeación y los objetivos}

En esta etapa se definen los objetivos y los recursos involucrados, se realiza una planeación de las actividades y una evaluación de riesgos. Tomando las anotaciones de Rodriguez (2003) ${ }^{40}$ y Kemp, Hollowood y Hort $(2011)^{41}$ y llevándolas al presente trabajo, es parte de la estrategia de marketing de un servicio como el de hotelería para este caso, el determinar claramente los siguientes elementos:

\footnotetext{
40 Ibid Rodríguez (2003)

${ }^{41}$ Ibid Kemp, Hollowood yHort (2011)
} 
- Plantear claramente los objetivos: Para qué se quiere tener una marca olfativa, como por ejemplo:

- Posicionar un elemento diferenciador que permita generar fidelidad entre los huéspedes de lujo.

- Permitir que el huésped tenga una experiencia sensorial que se refleje en la difusión de una imagen positiva.

- Generar recordación de marca.

- Los deseos y las necesidades que quiero satisfacer, que para este caso serán los de nuestro huésped de lujo; además de los beneficios racionales y psicológicos.

- Identificar los atributos más relevantes de incluir una fragancia dentro del hotel.

- Identificar claramente el Target group, a qué tipo de huéspedes se quiere llegar y segmentación del mismo (edad, género, entre otros).

- Que ventajas competitivas representa esta estrategia, y como contribuyen los objetivos de este proyecto a la imagen corporativa y a las estrategias de marketing y ventas del hotel.

- Identificar cual es el presupuesto con el que se cuenta para la planeación, puesta en marcha y evaluación del proyecto.

En esta etapa pueden incluirse encuestas como la siguiente:

Quiero conocer preferencias generales de mis huéspedes (antes de implementar):

Es muy útil hacer un sondeo general de las preferencias del target objetivo, en este caso, para nuestro huésped de lujo, podría plantearse una pregunta al momento del check in o check out como por ejemplo: Si tuviera que elegir entre un aroma para ambientar nuestro hotel, ¿cuál de las siguientes alternativas considera la de mayor interés? 

a. Una fragancia sutil a flores
b. Una fragancia fresca con connotación cítrica
c. Una fragancia con olor a madera
d. Una fragancia dulce como vainilla
e. Una fragancia frutal

Para esta pregunta pueden incluirse cintas olfativas con las alternativas para que el huésped sea el que elija la que más le agrade.

Otro posible pregunta podría plantearse de la siguiente manera:

Organice cada una de las siguientes alternativas de acuerdo a su preferencia siendo 1 la mejor y 5 la última opción, pensando en un aroma para ambientar las zonas sociales de nuestro hotel.

_. Una fragancia sutil a flores

_. Una fragancia fresca con connotación cítrica

_. Una fragancia con olor a madera

_. Una fragancia dulce como vainilla

_. Una fragancia frutal

\subsection{Tercera etapa, la estrategia de implementación}

De acuerdo con Curtis, Williams y Horwood $(1994)^{42}$, el marketing experimental se presenta como una herramienta del marketing que ofrece al consumidor no un producto, sino un beneficio. Para el caso del proyecto de implementación de una fragancia en el hotel de lujo, es fundamental realizar un proceso en el cual se involucren todos los interesados en el proyecto y se tenga una clara orientación a

${ }^{42}$ Curtis, T, Williams, D y Horwood, E. (1994). Introduction to perfumery. London. 
la satisfacción de las necesidades de estos exclusivos consumidores de servicios, los huéspedes de lujo.

Para el desarrollo de éste modelo se tomaron las anotaciones de Kerzner (2013) ${ }^{43}$, Rodriguez $(2003)^{44}$ y Kemp, Hollowood Y Hort $(2011)^{45}$ y aplicando sus conceptos al presente trabajo, en la etapa de implementación del proyecto es importante tener en cuenta los siguientes factores:

3.3.1 Identificación del perfil de usuario:

En este caso el usuario se trata del huésped al cual va dirigida la estrategia y el perfil puede ser uno u otro dependiendo de las actividades que realiza y de las motivaciones que tuvo para visitar el hotel. De esta forma podemos decir que, un mismo hotel puede tener uno o varios perfiles de huésped que interaccionan de distinta forma con la marca del hotel. Sin embargo para el desarrollo de una marca olfativa es importante unificar los factores más relevantes de esta relación huésped - hotel para crear una sola marca que represente los valores del establecimiento y le permita tener una identidad. A continuación se describen diferentes posibles conceptos de acuerdo al huésped de lujo y a la imagen de marca que un hotel de lujo podría transmitir.

Cabe notar que estos conceptos son ilustrativos a manera de ejemplo y que de acuerdo a cada proyecto de desarrollo de marca estos pueden ser diferentes. El esquema se desarrolló basado en las familias olfativas más relevantes Osmoz $(2013)^{46}$ y a la descripción de los hoteles y huéspedes de lujo mencionados en los anteriores capítulos.

\footnotetext{
${ }^{43}$ Ibid Kerzner (2013)

44 Ibid Rodriguez(2003)

${ }^{45}$ Ibid Kemp, Hollowood Y Hort (2011)

${ }^{46}$ Familia Olfativa. Osmoz. Recuperado de http://es.osmoz.com/enciclopedia/familias- olfativas. 2013.
} 
3.3.1.1 De acuerdo al tipo de huésped de lujo

- El ejecutivo o viajero de negocios: Podría tratarse de una fragancia sofisticada que refleje el perfil de este tipo de huésped, debe ser una fragancia unisex donde prevalezcan las notas amaderadas, especiadas con un toque de dulce y fresco que transmitan la identidad de lujo del hotel.

- El solitario: Por su personalidad podría hablarse de fragancias frescas incluidos aromas cítricos con limón, bergamota, toronja y herbales como la albahaca. Además podrían incluirse notas amaderadas como el sándalo y el cedro. Se sugiere que en caso de incluir cítricos sean mezclas de estos aromas para darle mayor carácter a la fragancia y que se sienta más compleja y sofisticada.

- El viajero familiar: Podrían sugerirse mezclas de fragancias complejas que no permitan definir el aroma con certeza, un bouquet de flores y frutas que sea sutil y agradable sería una buena alternativa.

- El turista en pareja: En este caso dependiendo del objetivo del turista podrían presentarse diferentes alternativas, cuando el turista visita al hotel con el objeto de disfrutar de un viaje romántico con su pareja, aromas florales con énfasis en aromas a rosa y algunos toques dulces acordes con el concepto del hotel. En el caso de ser una visita de amigos aromas más frescos o fusiones frutales con notas dulces podrían acompañar a los visitantes con un ambiente cálido y sofisticado.

El perfil del huésped de lujo: como ya se ha mencionado depende del tipo de hotel y de las características que puede percibir cada uno, siendo un caso único para cada caso. A continuación se ilustra un ejemplo de perfil de huésped en relación al aroma donde se representa en manera porcentual la relevancia de cada aroma en el total de la fragancia final. 
Figura 1 - Perfil de acuerdo al tipo de huésped

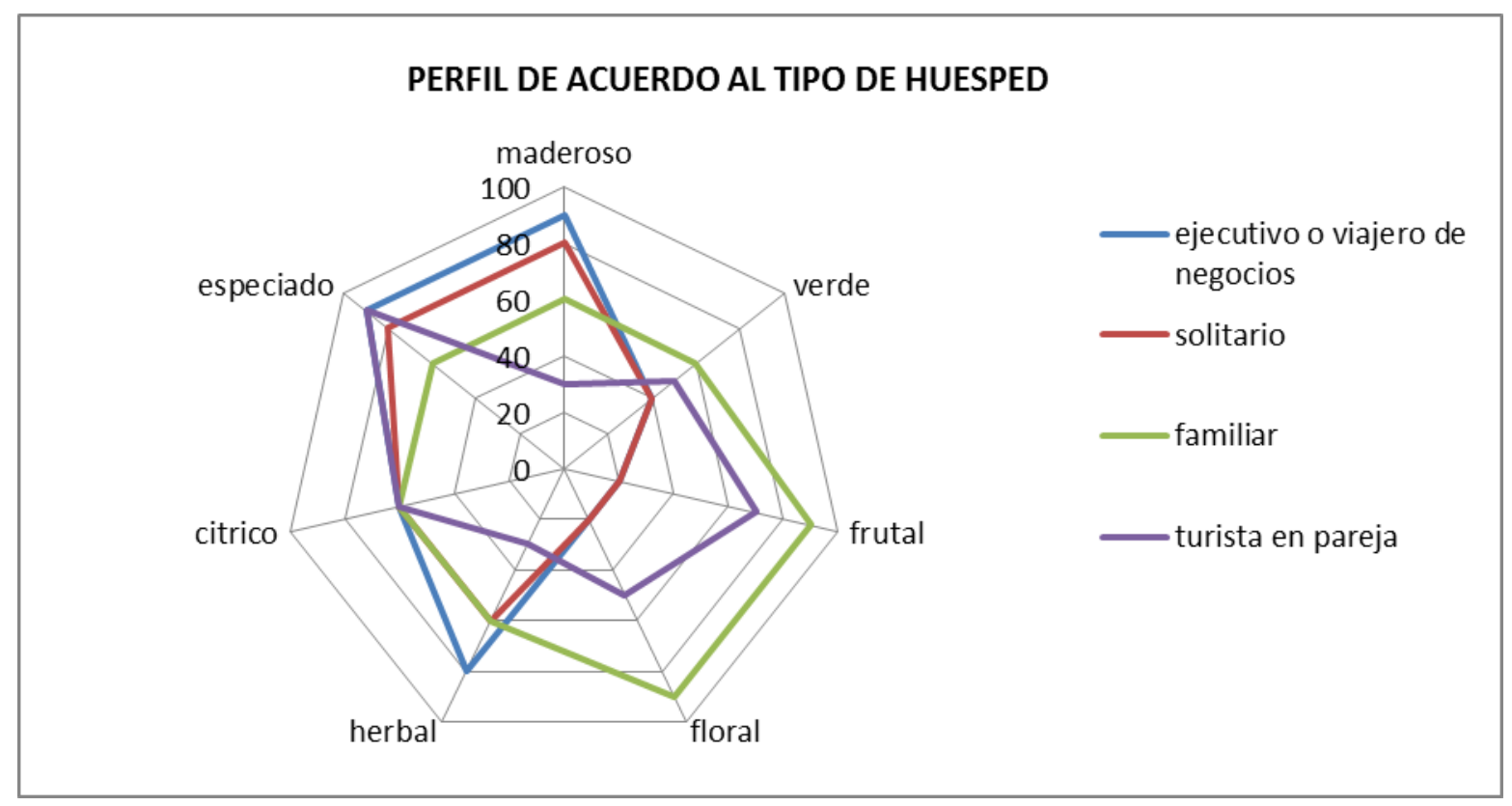

Fuente: Elaboración propia

\subsubsection{De acuerdo al concepto de marca}

Si el hotel tiene claros los valores que desea transmitir puede generar un concepto unificado que se proyecte en todas las áreas del hotel y refleje la imagen que desea comunicar el establecimiento. A continuación se dan algunos ejemplos de valores que se pueden transmitir a través de un aroma:

- Exclusividad y sofisticación: Fragancias amaderadas, tipo perfumería fina con notas complejas y que no sean fácilmente descritas, mezclas de materias primas sutiles que no saturen al huésped, con niveles medios de percepción para no causar una percepción desagradable. Fragancias amaderadas con sutiles notas florales, dulces y cítricas podrían ser una alternativa. 
- Vanguardista: Fragancias frescas y complejas con notas amaderadas, ámbar, marinas y cítricas son una opción que podría representar este tipo de hoteles con sistemas de difusión que transmitan modernidad.

- Eco Hotel, de la mano con la naturaleza: Fragancias con notas que representen la naturaleza, desde herbales como la manzanilla, cítricas como la bergamota, el limón y la naranja, hasta notas frutales con toques amaderados, de forma que representen el contacto con la naturaleza y lo verde.

- Tipo spa: Una alternativa podría incluir notas suaves y relajantes como manzanilla, lavanda y caléndula acompañados de vainilla, y algunas flores y maderas que transmitan sofisticación.

Cada hotel puede diseñar su propio perfil de acuerdo a sus objetivos y características, a continuación se muestra un ejemplo de perfil relacionado con el aroma.

Figura 2 - Perfil de acuerdo al concepto de Hotel de Lujo

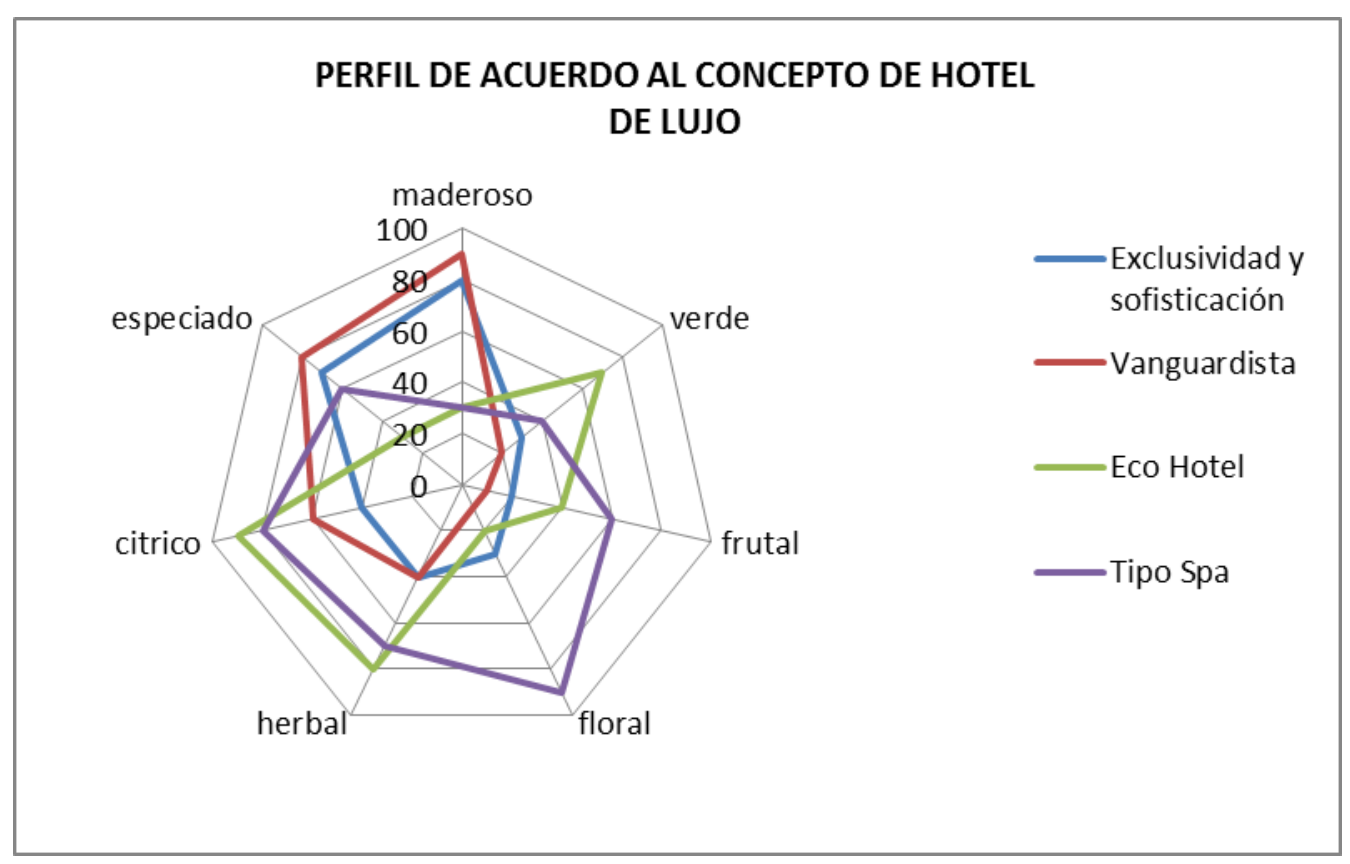

Fuente: Elaboración propia 
3.3.2 Selección de las áreas del hotel que se quieren aromatizar:

No es igual tener una fragancia en el lobby, que tener una fragancia en la habitación o baño. (ver tabla 2).

Algunos hoteles han incorporado fragancias en los diferentes espacios del establecimiento, sin embargo al momento de la elección del aroma es importante que aunque se seleccione una o varias fragancias, debe existir un objetivo y elemento en común que permita crear una identidad de marca que pueda percibirse a través del sentido del olfato. De esta forma el aroma reflejará los valores del hotel creando una atmosfera que permitirá cumplir con el objetivo planteado en un principio.

Cuando se trata de desarrollar una marca olfativa lo ideal es tener la misma fragancia en todos los espacios sociales, en caso de decidir ambientar uno solo, se sugiere ambientar el lobby o la habitación por estar en mayor contacto con el huésped.

En el caso de incorporar una fragancia en el área del lobby es importante tener en cuenta la funcionalidad del espacio, es decir que para este caso por ejemplo, debe seleccionarse una fragancia que transmita sensación de confort que le permita al huésped disfrutar de su estancia en esta área. Es el primer contacto con el huésped y por lo tanto lo ideal es impactar de forma positiva si se quieren obtener buenos resultados.

El área del baño debe reflejar limpieza, por lo que generalmente se utilizan aromas frescos y cítricos que estén direccionados a este objetivo. Las habitaciones son espacios más cerrados así que la frecuencia e intensidad de aplicación de la fragancia debe ser muy sutil para no saturar al huésped. Una buena alternativa para el segmento de hoteles de lujo es incluir más de una alternativa a elección 
del huésped, de esta manera el huésped siente un trato de exclusividad y podrá disfrutar del aroma que seleccionó.

\subsubsection{La selección de la fragancia:}

Si las etapas anteriores están bien definidas se pueden seleccionar dos o tres alternativas de aroma con el ánimo de tener más de una opción al momento de realizar un testeo, y de esta forma las partes involucradas pueden elegir.

De acuerdo con Curtis, Williams y Horwood $(1994)^{47}$ Se deben tener claros cuales son los atributos que se quieren transmitir a través de la incorporación de la fragancia, los cuales pueden verse en el siguiente diagrama.

Diagrama 1 - Atributos de la fragancia

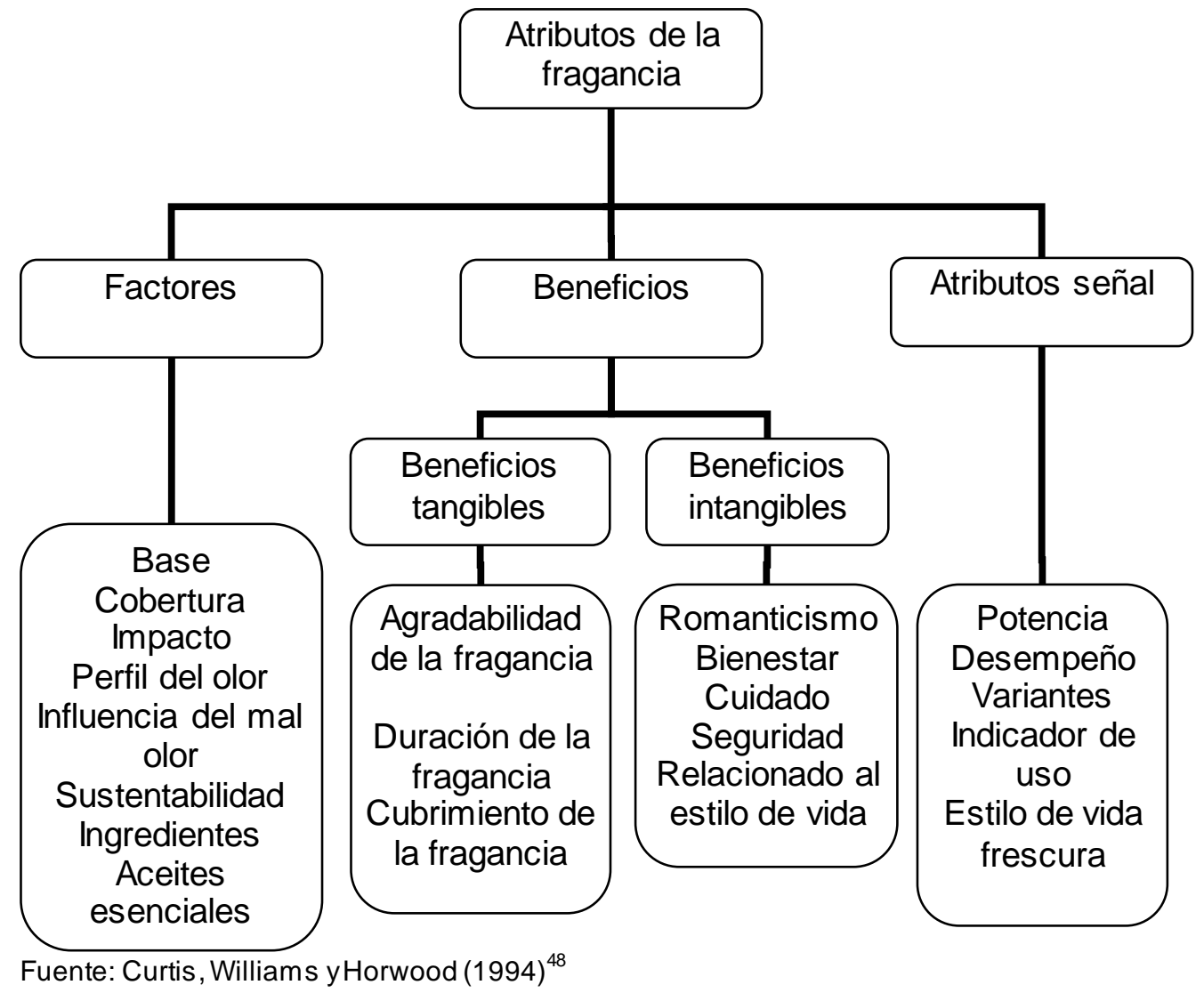

${ }^{47}$ Ibid Curtis, Williams yHorwood (1994) 
A continuación se muestra un cuadro de ejemplo donde se tomó información referente al efecto de diferentes aromas y se trasladó al ámbito de los posibles espacios de un hotel, esta información puede cambiar dependiendo del proyecto.

Tabla 2- Relación entre los aromas y los espacios de un hotel.

\begin{tabular}{|l|c|c|c|c|c|l|}
\hline & Habitación & Lobby & Gimnasio & Spa & Baños & \multicolumn{1}{|c|}{ Posibles Aromas } \\
\hline Tranquilidad/relax & $\mathrm{X}$ & $\mathrm{X}$ & & $\mathrm{X}$ & & $\begin{array}{l}\text { Lavanda, aromáticas, } \\
\text { jazmín, violeta, cedro }\end{array}$ \\
\hline Energizante & & & & & & $\begin{array}{l}\text { Ć́trico como naranja, } \\
\text { bergamota, limón, verdes, } \\
\text { herbales, canela, rosa }\end{array}$ \\
\hline Calidéz & $\mathrm{X}$ & $\mathrm{X}$ & & $\mathrm{X}$ & & $\begin{array}{l}\text { vainilla, maderas, } \\
\text { especias }\end{array}$ \\
\hline Armonía & $\mathrm{X}$ & $\mathrm{X}$ & & & & $\begin{array}{l}\text { Flores, frutas, lavanda, } \\
\text { sándalo, vainilla }\end{array}$ \\
\hline Limpieza/Frescura & & & $\mathrm{X}$ & & $\mathrm{X}$ & $\begin{array}{l}\text { Ć́tricos, notas marinas, } \\
\text { aloe, pino }\end{array}$ \\
\hline
\end{tabular}

Fuente: Adaptado de libro de velas. Rossi y Leon (2000) ${ }^{49}$

Existen fragancias que generan sensación de bienestar y calidez, como las vainillas y algunas maderas, otras transmiten frescura como las cítricas (limón, naranja, bergamota, etc.), otras son tranquilizantes como la lavanda y la manzanilla. Así que dependiendo del mensaje que se quiere transmitir será la fragancia seleccionada.

Si el objetivo del hotel va direccionado a la selección de un aroma genérico, podría elegir alguna de las siguientes alternativas:

- Incorporar una fragancia para cada espacio: Es decir aromatizar cada uno de los ambientes, lobby, halls, salas de descanso, etc. Cada una con una fragancia diferente, sin olvidar que deben tener un factor común que

\footnotetext{
${ }^{48}$ Ibid Curtis, Williams yHorwood (1994)

${ }^{49}$ Rossi, My Leon, .F. (2000). El Libro De Velas. Editorial Albatros. Buenos Aires Argentina
} 
permita al huésped generar una percepción de los atributos del hotel y ser recordado.

- Por temporadas: Puede incluir temáticas por periodos de tiempo definidos, vinculadas al cambio de estación como fragancia de invierno, primavera, verano y otoño.

- Fragancias temáticas: Se podrían incluir fragancias de acuerdo a eventos y celebraciones en determinados periodos de tiempo, tales como día de San Valentín, mundial de fútbol, celebración de algún festival, fragancia de carnaval, etc.

Es importante tener en cuenta el tipo de hotel. Los hoteles boutique son ambientes generalmente más chicos, en los cuales el objetivo va en línea con la exclusividad, de manera que para las habitaciones el aroma puede ser parte del criterio de selección del huésped. Incluir en la lista de preferencias y en el catálogo del hotel alternativas para ambientar. Esta es una estrategia que permitirá al huésped sentirse único, y recordar el hotel de manera positiva.

\subsubsection{Selección del método de difusión:}

La selección del método de difusión de la fragancia depende en gran parte de dos aspectos, el presupuesto y el área de difusión (dimensión del espacio). El precio entre un método y otro puede tener grandes variaciones, ya que existen métodos económicos para espacios chicos como las velas y los difusores de bambú, hasta algunos más costosos y sofisticados como difusión a través de sistemas de ventilación y aire acondicionado. 
También existen sistemas intermedios como los aerosoles, práctica muy común en los almacenes de retail, hospitales y centros de atención al público, por su facilidad de aplicación y costo.

Evaluación de costos: El costo de la implementación de un sistema de aromatización es diferente para cada uno de los casos y para ello es muy importante tener en claro los siguientes elementos:

- Área y dimensiones del espacio a aromatizar

- Sistema de difusión (difusores de bambú, velas, aerosol, etc.)

- Frecuencia de uso.

- Nivel de intensidad en el aroma deseado.

- Tipo de fragancia, nota olfativa.

Si se tiene la toda esta información la evaluación de costos es mucho más sencilla, sin embargo durante los testeos es posible hacer ajustes para determinar el valor más adecuado para cada caso, dependiendo de la necesidad y del presupuesto estimado.

3.4 Cuarta etapa, ejecución del proyecto, el seguimiento, el método de evaluación y el análisis de datos.

Siguiendo los procesos de acuerdo con Kerzner (2013) ${ }^{50}$, Rodriguez $(2003)^{51} \mathrm{y}$ Kemp, Hollowood y Hort $(2011)^{52}$ la última parte, es una etapa de gran importancia

50 Ibid Kerzner (2013)

${ }^{51}$ lbid Rodriguez (2003)

52 lbid Kemp, Hollowood y Hort (2011) 
ya que es la etapa en la cual se realiza la evaluación mediante el método de evaluación seleccionado y el análisis de datos.

Una vez identificados los factores que intervienen en la etapa anterior y se pone a prueba el proyecto se sugiere evaluar periódicamente el desempeño del aroma y el sistema seleccionado. Esta evaluación puede realizarse mediante encuestas en las cuales pueden participar huéspedes, administradores, dueños, gerentes de marketing, área de comunicaciones y en general cualquier persona que pueda suministrar información referente al desempeño de la fragancia para así poder determinar si la estrategia ha tenido resultados positivos de acuerdo con los objetivos planteados en las etapas iniciales. De acuerdo a esta información también se pueden realizar ajustes a la fragancia, al sistema de difusión, al lugar de aplicación y al tiempo de difusión del aroma.

- Estas evaluaciones periódicas pueden ser mediante monitoreos cualitativos, cuantitativos o cuali- cuantitativos.

- Deben seleccionarse métodos de evaluación adecuados para el lugar, el presupuesto y los objetivos a alcanzar, pueden ser monádicos, a ciegas, etc.

- Debe seleccionarse el Target Group al cual se le realizara el estudio.

- Debe identificarse el alcance geográfico del estudio.

- Debe identificarse el tipo de muestreo requerido, el tamaño de la muestra.

Una vez realizado el testeo hay una etapa de ajustes donde es importante evaluar:

- Análisis de varianzas e impactos: Debe revisarse si en alguna de las actividades del proyecto han surgido cambios y cuáles son los impactos que éstos pueden generarle al proyecto (costos, tiempo, beneficios, etc.)

- Tomar acciones de acuerdo a los resultados.

- Costos implicados, ajustes en los mismos, presupuesto 
- Ajustes: De acuerdo con la evaluación realizada pueden realizarse algunos ajustes a las actividades siguientes, tales como cambio en la fragancia, método de difusión del aroma, cambio en la frecuencia de uso, y otros. Se deben identificar los puntos positivos y las etapas a mejorar.

- Tomar decisiones respecto a la implementación de la fragancia y plan de monitoreo posterior.

Para tener claro que se cumplirán las expectativas se sugiere realizar testeos sensoriales y/o encuestas antes de implementar en su totalidad la difusión de un aroma.

Pueden evaluarse aspectos como agradabilidad y fuerza de la fragancia, adicionalmente es posible preguntar si el aroma que se percibe lo relaciona claramente con la marca, esto en el caso de que el objetivo sea desarrollar una marca olfativa exclusiva, en caso de que el objetivo de incorporar una fragancia sea parte de la estrategia de fidelización pueden realizarse preguntas relacionadas con la agradabilidad y sensación que tienen los huéspedes al estar un tiempo en contacto con la misma. Con base en estos resultados pueden identificarse las frecuencias de aplicación y el método de difusión.

Para la evaluación de la fragancia en esta etapa pueden utilizarse diferentes técnicas de evaluación sensorial dependiendo del objetivo. A continuación se dan algunas alternativas con base en posibles objetivos:

Deseo saber cómo relacionan mis huéspedes la fragancia con la imagen del Hotel. Cuando el objetivo está claramente direccionado a la creación de marca olfativa es importante conocer si los huéspedes y visitantes del hotel relacionan la fragancia con los valores que intenta transmitir a través del marketing sensorial. Un ejemplo de pregunta podría ser: 
¿Cuál de los siguientes enunciados describen mejor el hotel cuando piensa en el ambiente y olor del mismo?

a. Es un ambiente cálido, tranquilo y sofisticado

b. Es un ambiente fresco

c. Es un ambiente alegre

d. Es un ambiente frio y sobrio.

e. Ninguna de las anteriores

Quiero saber la intensidad de percepción de la fragancia: responda a la siguiente pregunta si percibe algún olor en el ambiente, marque con una $x$ el nivel de intensidad con el que percibe la fragancia del lugar:

5. Muy fuerte

4. Fuerte

3. Nivel medio, ni fuerte ni débil, ideal

2. Débil

1. Muy Débil

Quiero saber el grado de aceptación de la fragancia: Para ello podría realizarse una encuesta de agradabilidad sencilla de cinco puntos como la siguiente: ¿Qué tanto le agrada la fragancia de nuestro hotel?

5. Muy agradable

4. Agradable

3. Me es indiferente

2. Poco agradable

1. Desagradable

Quiero saber si a mis huéspedes les agrada la fragancia: En este caso una pregunta relacionada con la agradabilidad podría ser suficiente, esta puede 
incluirse dentro del formulario al final de la estadía o dentro de la encuesta de satisfacción al momento de hacer el check out. Un ejemplo de pregunta es:

¿Cómo percibe el aroma en general del hotel?, opciones: Agradable, poco agradable. ¿Cree que el aroma del hotel tuvo algún efecto positivo en su estadía?

\subsection{Quinta etapa de finalización y cierre}

Este es el final, la última etapa de todo el proyecto de implementación de un aroma en un hotel de lujo, es aquí donde se realiza una verificación de que todo el trabajo se haya realizado, se hace un cierre financiero y se dan las conclusiones y sugerencias del proyecto.

Para dar una vista general de todas las etapas del proyecto se muestra a continuación un diagrama para el proyecto del presente trabajo basado en la metodología propuesta por Meredith Jack R y Mantel $(2012)^{53}$.

${ }^{53}$ Ibid Meredith Jack R y Mantel (2012) 
Diagrama 2 - Implementación de un odotipo en un hotel de lujo

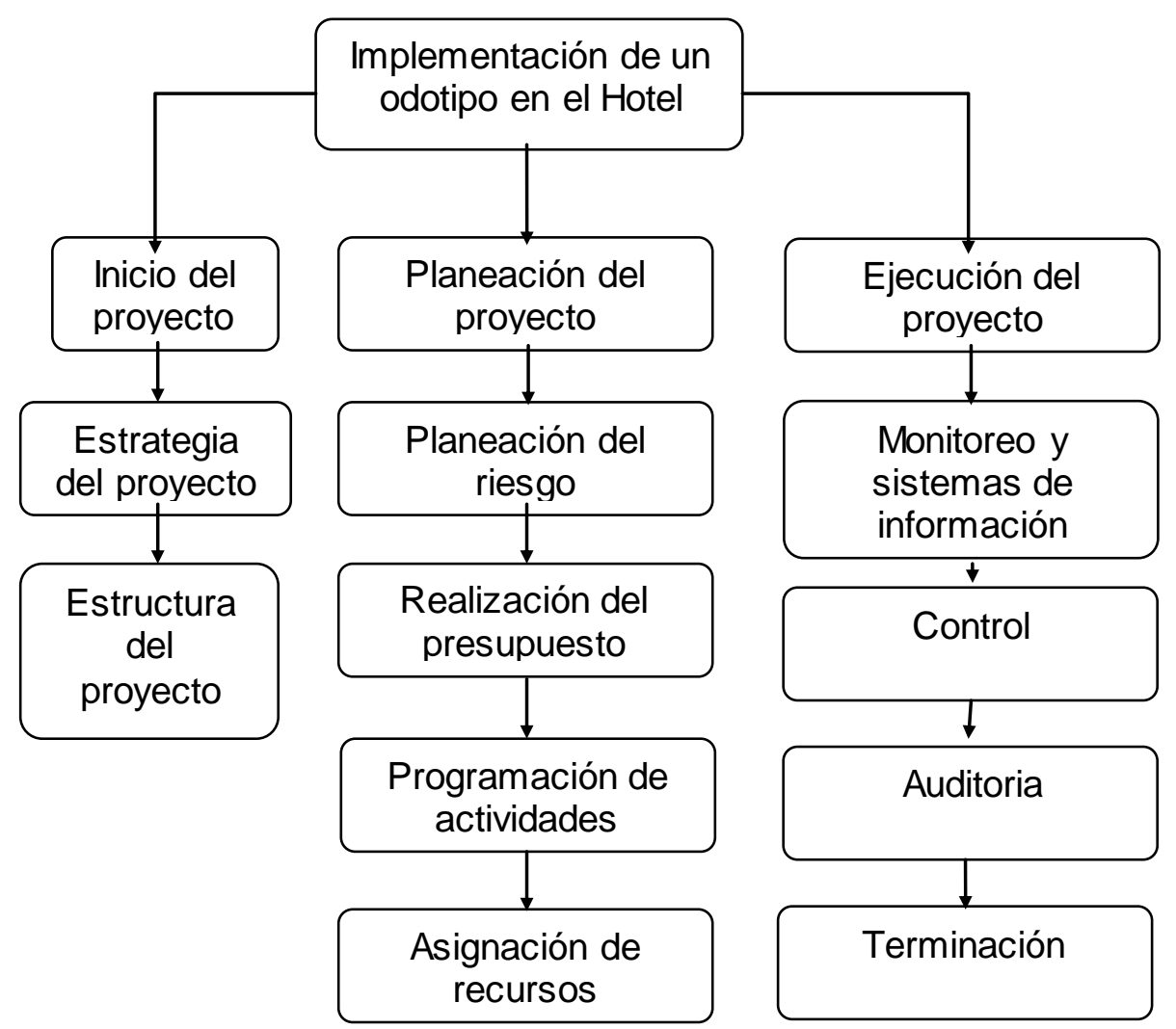

Fuente: Adaptado de Meredith y Mantel (2012) ${ }^{54}$.

Una vez seguido todo el proceso de implementación pueden realizarse evaluaciones periódicas de la metodología utilizada, las fragancias seleccionadas y se pueden realizar actualizaciones de acuerdo a las necesidades de cada hotel, de las tendencias del mercado y de los nuevos conceptos que se quieran incorporar.

Finalmente podría decirse que siguiendo las etapas mencionadas anteriormente se daría paso a la implementación de una estrategia de marketing olfativo en un hotel de lujo.

54 Ibid Meredith Jack R y Mantel (2012) 
CAPTULO IV

4. CASO DE APLICACIÓN: HOTEL BO BO, UN HOTEL BOUTIQUE DE LUJO.

The BoBo meritocracy will not be easily toppled, even if some group of people were to rise up and conclude that it should be. So let's go off and survey the manners and mores of today's dominant social class. ".

- David Brooks -

El Hotel Resort Valley Inn \& Spa en Los Ángeles utiliza aromas como lavanda y naranja para ambientar sus espacios, El Mandalay Bay Hotel \& Casino en Las Vegas sigue esta estrategia sensorial con fragancias especiadas y notas a coco en algunos ambientes del lugar, en el The Scent un hotel en Tailandia sobresalen notas aromáticas y el Asia Gardens Hotels and thai spa tiene una fragancia compuesta por aromas de incienso, cariofileno, cedro y cadineno.

Aunque algunos hoteles han implementado estas técnicas de marketing olfativo siguen siendo pocos los que han aprovechado esta herramienta como parte de sus estrategias de marketing.

Parece ser una tendencia que en algunos hoteles especialmente el sector de lujo se incluyan uno o varios aromas en sus espacios, sin embargo muchas veces la etapa de implementación se lleva a cabo sin desarrollar etapas previas de 
evaluación que contribuyen a alcanzar el objetivo planteado, permitiendo generar valor a su marca, es decir, que generalmente se incluye un aroma sin tener en cuenta los valores que desea transmitir la marca, para que sus huéspedes y visitantes recuerden al lugar por la experiencia sensorial del lugar. Es importante resaltar que no es lo mismo ambientar un hotel de manera aleatoria que incorporar un aroma que esté ligado al concepto y marca del hotel. Es por ello que en el presente capítulo se intentará describir un caso real en un Hotel Boutique de lujo mediante la aplicación del modelo planteado en el anterior capitulo, de esta forma se presentara una propuesta de marketing olfativo para un hotel boutique de lujo con el objeto de mejorar su identidad e imagen corporativa brindándole al huésped una experiencia sensorial que involucra el sentido del olfato.

4.1 Siguiendo el modelo, proceso de implementación de una fragancia en el Hotel Bo Bo en Buenos Aires.

Como se ha venido describiendo a lo largo del presente capítulo, el proceso sugerido para la implementación de una fragancia en un hotel de lujo requiere de una serie de etapas que permiten identificar los objetivos de los involucrados en dicho proyecto y utilizar las herramientas necesarias y adecuadas para el mismo.

A continuación se describirá dicho proceso aplicado a un hotel boutique de lujo en la ciudad de Buenos Aires, el Bo Bo Hotel.

\subsubsection{Primera etapa: El inicio del proyecto}

El primer paso para realizar este proyecto fue contactar al hotel, posteriormente se realizó una reunión con administradores y propietarios para darles a conocer la idea de implementar una estrategia de marketing olfativo, y así saber si el hotel 
estaba interesado en desarrollar este proyecto. Una vez hecho el contacto se estructuró un plan de trabajo y se comenzó a trabajar en conjunto. Se definió que se presentaría una propuesta de odotipo para el hotel incluyendo fragancias, métodos de difusión, espacios, entre otros, para que una vez presentada la propuesta el Hotel tomara la decisión y tiempos en los cuales lo implementaría en su totalidad.

Una vez definidos los aspectos generales del proyecto se comenzó la recolección de información mediante información en la página web, folletos del hotel e información suministrada por los propietarios y administradores del lugar. A continuación se enumeran los puntos más relevantes del Hotel incluyendo información general de su estructura y servicios.

\section{HOTEL BO BO ${ }^{55}$}

a. El nombre del hotel: Bo Bo fue nombrado así en honor al escritor estadounidense David Brooks, "Bobos en el paraíso ", significa Bourgeois Bohemians, Bohemios y Burgueses, refiere al contexto de los años sesenta y ochenta donde se vive la creatividad y la espontaneidad de los bohemios y el trabajo y afán de prosperidad de los burgueses. De allí toma su nombre este hotel con clase.

\footnotetext{
${ }^{55}$ Información general del hotel Bo Bo. Recuperado el 10 de julio de http://www.bobohotel.com/
} 
b. El logo:

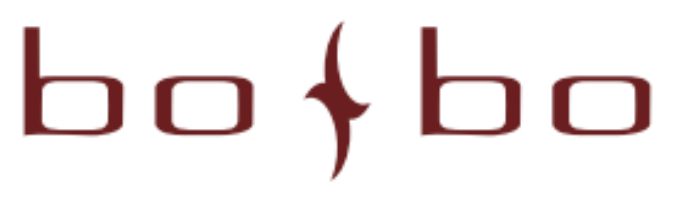

bourgeois bohemian

c. Su ubicación: se encuentra localizado en el corazón de Palermo Soho, un barrio de clase alta de Buenos Aires rodeado de restaurantes, casas de diseñadores y boutiques, restaurantes de lujo, bares, cafeterías y hoteles que se mezclan entre sí, un barrio donde la moda es un referente.

Por encontrarse localizado en la ciudad de Buenos Aires, es importante tener en cuenta que es una ciudad donde el clima tiene la influencia de las cuatro estaciones, con cambios de temperatura entre una y otra que influirán en el proceso de selección y uso.

d. Infraestructura: El hotel se encuentra construido sobre una antigua casa que se remonta al año 1927, Juan Bottan, su diseñador junto a la fecha se nombran en una placa del edificio remodelado. Los cambios incluyeron entre sus detalles modernos y elegantes acabados que transmiten lujo y sofisticación.

El hotel cuenta con un elegante restaurante, llamado como el hotel, Bo Bo donde se ofrece un exquisito menú, adecuado para sus huéspedes y visitantes.

e. Las habitaciones: Este hotel boutique cuenta con 15 habitaciones de lujo, cada una decorada con materiales, colores y elementos de diseño elegantes y diferentes haciendo única a cada una de las habitaciones y convirtiendo a este hotel en un hotel boutique temático. Las habitaciones se 
encuentran categorizadas en Superior, Deluxe y Senior suites de las cuales 13 de las 15 habitaciones del hotel cuentan con terraza privada. La decoración incluye diseños diferentes en cada una de las habitaciones, cuyos nombres se mencionan a continuación. clásica, art deco, racionalista, vintage, rústica, minimalista, pop, tecno, ecléctica, mediterránea, Argentina, oriental, entre otras.

Actividades: El hotel ofrece a sus visitantes gran variedad de actividades entre las cuales se incluyen, city tours temáticos y privados como tour por la ciudad de Buenos Aires (grupal o individual), tour de la ciudad en bicicleta, día de compras, día de campo, polo, golf, fútbol, pesca deportiva, show de tango, clases de tango y de yoga. También incluyen servicio de masajes en la habitación y la opción de gimnasio y spa (fuera de la propiedad).

Además tienen entre sus alternativas viajes a Colonia, paseos en barco y velero, paseos en globo, etc.

Otros servicios: Parte del servicio de exclusividad en este hotel incluye alternativas como personal shopper, reserva de espectáculos y en restaurantes, alquiler de autos, transporte privado desde y hacia el aeropuerto, alquiler de celulares y clases de español.

Restaurante: El restaurante Bo Bo ubicado en la primera planta del hotel donde se transmite un ambiente tranquilo y con clase ofrece un amplio menú, con alternativas especiales para sus exquisitos huéspedes. 


\subsubsection{Segunda etapa: La planeación y los objetivos}

En esta etapa se fijaron los objetivos en conjunto con los dueños y administradores, se habló de los valores de lujo, exclusividad y buen servicio que distinguen al hotel y se recorrieron los diferentes ambientes del mismo.

De esta forma se determinó como objetivo desarrollar en el presente proyecto:

- Crear un ambiente más cálido dentro del mismo, donde los huéspedes del Bo Bo puedan sentir un ambiente agradable y sofisticado propio del lugar, de forma que las fragancias reflejen claramente la imagen y decoración del hotel. Con este proyecto también se pretende mejorar la percepción de la calidad de los servicios que ofrece el hotel al tener un acercamiento sensorial con el huésped.

Siguiendo el anterior enunciado se puede decir que el hotel pretende que el huésped perciba como beneficio racional, la tarifa pagada es acorde a la experiencia que puede tener dentro del hotel y como beneficio psicológico que le permita recordarlo de manera positiva.

El target group Bo Bo, está representado por un huésped de lujo, joven, que gusta de viajar, extranjero y con una condición social que le permite pagar las tarifas ofrecidas.

Una vez definidos estos puntos, se da paso a la siguiente etapa. 


\subsubsection{Tercera etapa: La estrategia de implementación}

Se realizaron varias visitas al hotel, se evaluaron los ambientes, y de acuerdo a la información recolectada durante las visitas se identificaron los siguientes factores:

Exclusividad y sofisticación: a través de una mezcla entre lo moderno y lo conservador, el hotel cuenta con habitaciones distribuidas en dos sectores, una parte antigua que pertenece a la casa original, donde se conservan los detalles y otra más moderna, con remodelaciones de la época. Las dos partes del hotel aunque diferentes en su forma, transmiten claramente un sentido de exclusividad y sofisticación a través de los detalles del mobiliario, la distribución de los espacios y los colores del lugar.

Perfil del Huésped de lujo del Hotel Bo Bo: El Huésped Bo Bo se caracteriza por ser un huésped exigente, donde el servicio se constituye en un elemento claramente percibido por el huésped de lujo que busca tener una experiencia de viaje única y placentera mediante un alto nivel de atención y servicio.

Figura 3 - Perfil del huésped BO BO

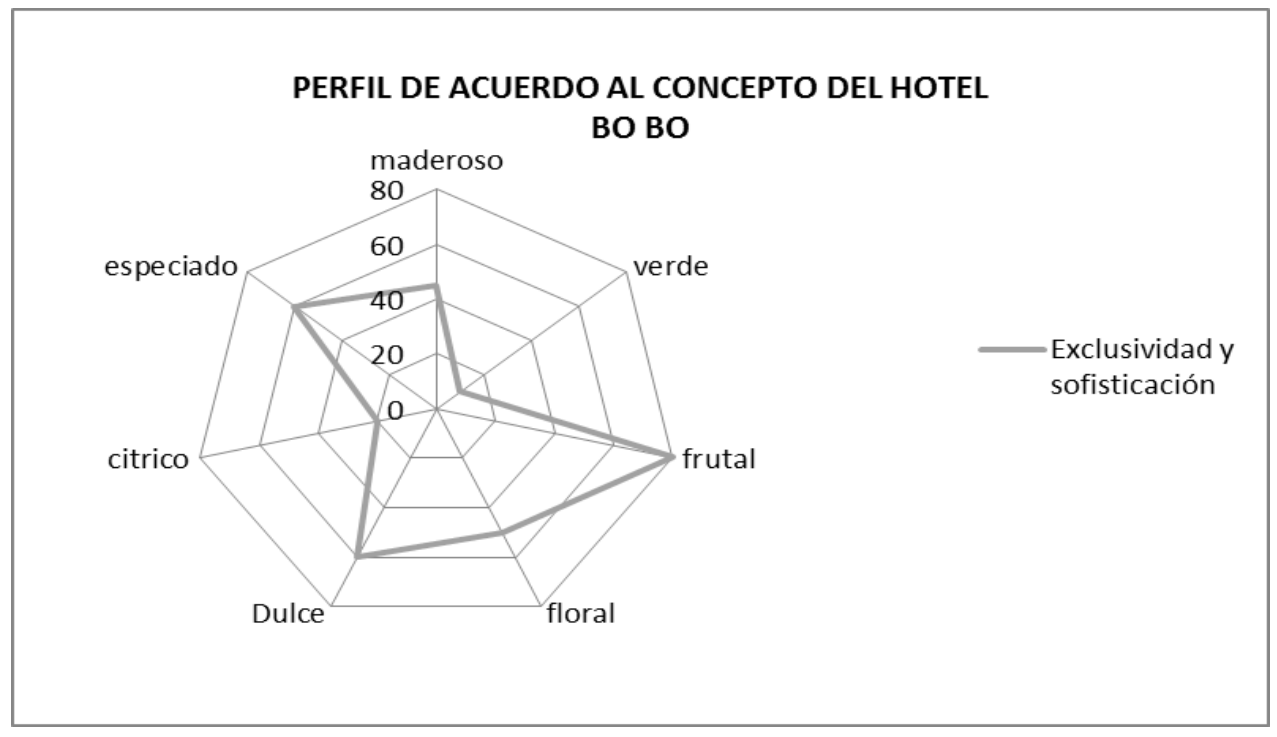

Fuente: Elaboración propia 
A continuación se listan algunos insights de este huésped de lujo Bo Bo:

- No quiero un hotel de cadena para todos, quiero un servicio personalizado y exclusivo donde me asesoren a la hora de organizar mí recorrido por el lugar y las actividades que puedo realizar.

- Vamos de vacaciones con mi pareja, queremos vivir una experiencia única e inolvidable en un lugar muy agradable con buena atención.

- No quiero un gran hotel con mucha gente, quiero salir de viaje pero sentirme como en casa.

- Quiero un hotel que este ubicado en un lugar privilegiado de fácil acceso, y que me ofrezca una variada oferta gastronómica y actividades culturales propias de la ciudad.

El tipo de huéspedes que más frecuentan el hotel es:

- El turista en pareja

4.1.3.1 Selección de las áreas del hotel que se quieren aromatizar:

En esta etapa se realizó un diagnóstico inicial de cada una de las áreas a aromatizar, encontrando lo siguiente:

- El lobby del hotel: Actualmente se percibe un aroma limón, fresco, sin muchos matices, sin embargo no es un olor que transmita los valores de la marca y no es el mismo siempre. Algunas veces no se percibe ningún aroma. 
En la decoración predominan los colores negro, blanco y rojo, acompañados de detalles y mobiliario en madera que muestran sofisticación, elegancia y tranquilidad. Es un espacio amplio con mucha luz y algunas plantas, el lugar tiene gran flujo de aire proveniente de la puerta de entrada y las ventanas, convirtiéndose en un factor importante al momento de seleccionar el tipo de fragancia y la ubicación de la misma para no perder la sensación de percepción del mismo.

- La entrada del restaurante: Es otra entrada al lugar, un lugar chico, pero el trayecto que permite llamar la atención de quienes no han entrado al restaurante. Durante la visita no se percibía ningún olor

- La terraza del restaurante: es un ambiente amplio y al aire libre rodeado de plantas. Las mesas y muebles son de madera.

- La sala de TV y lectura: un lugar chico que transmite calidez, rodeado de colores marrón provenientes de los muebles, pisos y decoración (libros, televisor), con una gran puerta ventana que permite visualizar una de las terrazas del hotel, un lugar perfecto para estar tranquilo y disfrutar de una película o un buen libro.

- Las habitaciones: Aunque todas tienen una decoración única con diseños diferentes, los valores que intentan transmitir en general guardan entre si algunos puntos en común, son lugares exclusivos, agradables, elegantes, modernos, tienen terrazas privadas, baños amplios incluso algunas de estas cuentan con jacuzzi.

Durante la visita no hay impacto al entrar no se siente un olor en particular, sin embargo hay una pequeña percepción al aroma propio del mobiliario que no llaman la atención. 


\subsubsection{La selección de la fragancia:}

En esta etapa de acuerdo a la evaluación inicial se definió que la calidez, el confort, la armonía y la sofisticación serían los factores que definirían el aroma del Hotel, de forma que se realizaron varias pruebas en los diferentes espacios del hotel para evaluar la intensidad y agradabilidad de la fragancia, y de esta forma poder definir la fragancia más adecuado para aromatizar las áreas comunes del Hotel.

Después de realizar una preselección de las fragancias se incluyeron para la evaluación: Una fragancia de frutos rojos con notas predominantes a blackberry, una fragancia con notas vainilla y almizcle, y una fragancia frutal con notas a durazno. Todas conservando la calidez y el concepto de sofisticación.

Una vez realizada la pre evaluación, se definió que se utilizarían dos fragancias en las áreas sociales con características similares para permitir que ésta se incorporara como identidad del lugar en armonía con los valores del hotel. Por otra parte, se seleccionaron dos alternativas para las habitaciones siendo estas fragancias florales y frutales con toques dulces para no saturar, manteniéndose alineadas con las fragancias seleccionadas para ambientar las otras áreas del hotel.

Descripción de las fragancias Bo Bo para los espacios comunes:

Fragancia A: Sobresalen las notas frutales y frescas del durazno, en medio de notas vainilla, almizcladas y amaderadas que transmiten calidez, confort y sofisticación.

Fragancia B: Fragancia almizclada con notables notas cálidas provenientes de la vainilla, con notas florales y amaderadas en el fondo. 
Gráfico 1 - Triangulo olfativo fragancias ambientes comunes hotel Bo Bo
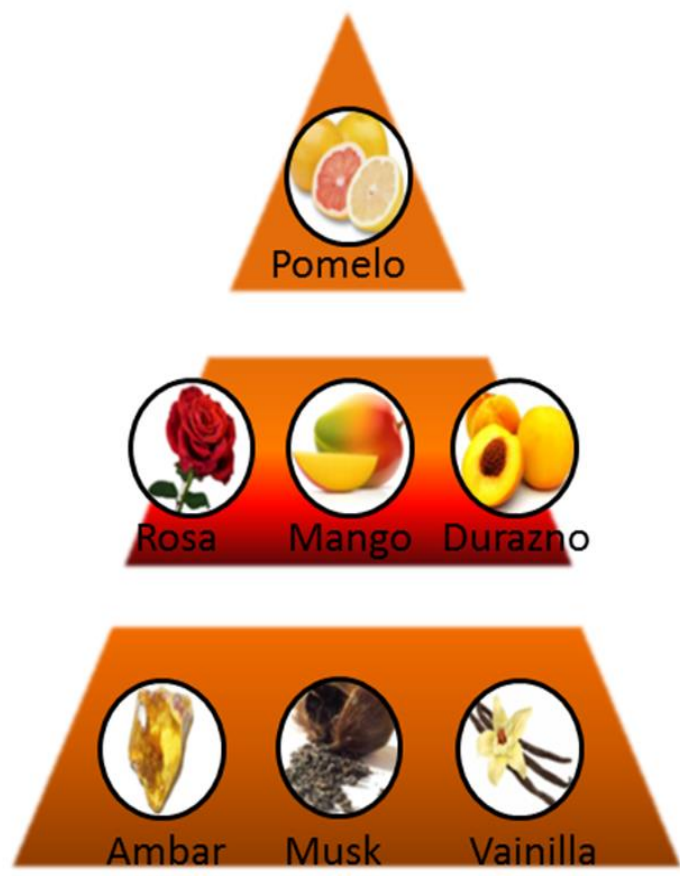

Fragancia Bo Bo A
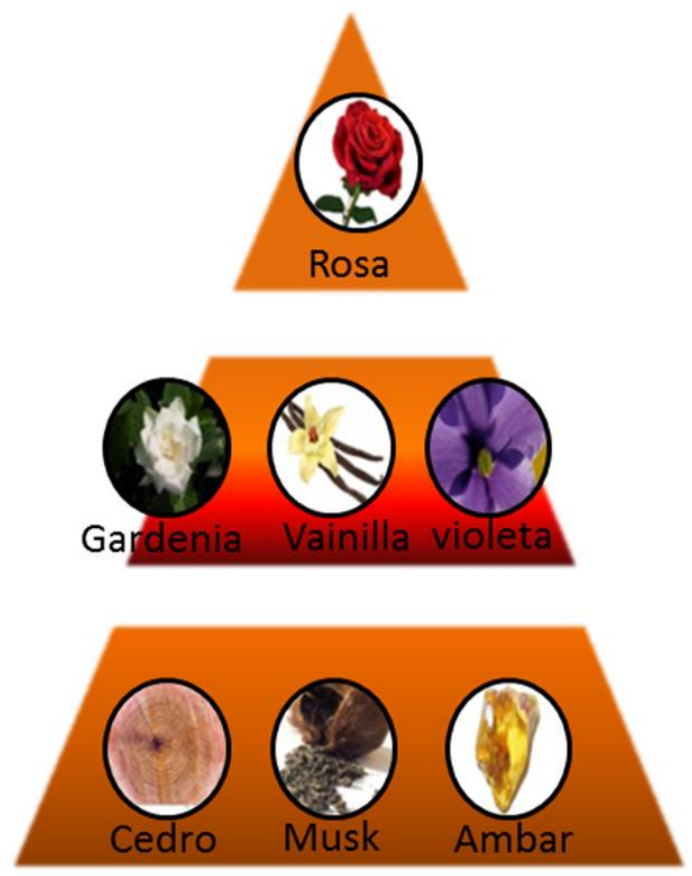

Fragancia Bo Bo B

Fuente: Elaboración propia

Fragancias para los difusores de bambú de las habitaciones:

La fragancia C: Es una fragancia floral con notas de roja y jazmín.

La fragancia D: Es una fragancia frutal con notas algunas notas dulces y frescas.

\subsubsection{Selección del método de difusión:}

Por tratarse de un hotel boutique, donde los espacios tienen áreas pequeñas, se realizó una evaluación de los métodos adecuados para este tipo de áreas por su difusión y costos, seleccionando los siguientes como los más adecuadas de acuerdo a las características de cada uno de los ambientes: 
- El lobby del hotel: hornito eléctrico ubicado cerca de una conexión eléctrica para no generar impacto negativo visual por los cables y en el centro para permitir la difusión del aroma.

- La entrada del restaurante: hornito eléctrico ubicado a uno de los costados de la entrada cerca de la conexión eléctrica disponible.

- La terraza del restaurante: Se decidió no incorporar aromas debido a que es un espacio dedicado a comer y los aromas del restaurante definen el ambiente del lugar.

- La sala de TV y lectura: Hornito eléctrico ubicado en una de las esquinas del espacio para permitir su conexión y la difusión del aroma sin que interfiera con la decoración.

- Las habitaciones: difusores de bambú, teniendo en cuenta que se quiere tener una sensación agradable sin que el aroma sature el ambiente y que sea fácilmente reubicado en caso de que el huésped quisiese moverlo.

Por otra parte se definió incluir como complemento de la estrategia la incorporación de amenities que incluyan aromas y empaques sofisticados acordes al concepto del hotel.

- Los pasillos: Se sugiere utilizar aerosoles en spray automáticos con una frecuencia moderada (15 - 20 minutos aproximadamente) para no saturar el ambiente permitiendo que se mantenga un aroma en el sector. 


\subsubsection{Evaluación de costos:}

El hotel tiene un presupuesto definido, el cual es acorde a la dimensión del hotel. En consecuencia se seleccionó un método de difusión que se adapta a sus necesidades presupuestarias y de acuerdo con la frecuencia de uso se presumieron valores medios acordes a los estimados para este proyecto. Se tomaron las siguientes variables:

- Sistema de difusión (difusores de bambú, sprays, aromatizadores de hornito).

- Frecuencia de uso: Es diferente dependiendo del método de aplicación. Difusores de bambú (cada vez que se utilice la habitación). Sprays (cada 15 a 20 minutos). Hornitos eléctricos (durante el día, aplicación cada 4 horas)

- Nivel de intensidad en el aroma deseado: nivel medio para no saturar al huésped.

- Tipo de fragancia, nota olfativa. De acuerdo al anterior punto "selección de fragancia".

- Se presentaron dos propuestas de costos donde se evaluaron diferentes proveedores.

4.1.4 Cuarta etapa: Ejecución del proyecto, el seguimiento, el método de evaluación y el análisis de datos.

Cuando se realizó la puesta en marcha de las fragancias se tenían algunas dudas sobre qué tipo de fragancia, el método de difusión y sobre todo el costo que tendría la implementación del proyecto. Sin embargo durante el proceso de desarrollo del proyecto se tomaron las decisiones de acuerdo a las necesidades del hotel, dentro de las cuales cabe la pena resaltar el interés por caracterizar sus 
áreas como lujosas y sofisticadas en un ambiente de buen servicio, rodeado de una serie de elementos que contribuyen a brindar al huésped una experiencia única. Sus huéspedes, la mayor parte turistas, que viajan en pareja o con amigos por vacaciones o con la intención de celebrar su luna de miel o alguna ocasión especial, buscan vivir una experiencia inolvidable en un lugar exclusivo donde cada habitación es diferente a las otras, y los ambientes lugares ideales para disfrutar de su estadía.

La propuesta olfativa pretende complementar esta experiencia y después de realizar el proceso de selección se obtuvo el siguiente panorama del hotel:

La recepción y lobby, la puerta de entrada y primera impresión está constituida por una fragancia frutal con notas durazno que transmiten calidez y confort. Los pasillos aromatizados con sprays tienen aromas con notas frutales y vainilla siguiendo la misma tendencia.

La sala de televisión y lectura invita a sus habitantes a pasar una tarde tranquila con la compañía de una buena película o un buen libro en un ambiente envuelto en la fragancia frutal con notas a durazno y vainilla manteniendo la misma línea de la fragancia del lobby.

Para las habitaciones se seleccionaron dos aromas con la intención de conservar los valores del lugar complementando la intención de transmitir los valores de sofisticación, un aroma que permita a sus huéspedes tener una experiencia agradable de forma que puedan recordar al Hotel Bo Bo de manera positiva.

En general se percibe un aroma cálido sin saturar el sentido del olfato permitiendo que la marca del hotel conserve las características de buen servicio acompañado por un ambiente agradable y sofisticado de acuerdo a los objetivos planteados. 


\subsubsection{Quinta etapa de finalización y cierre}

Después de entregar la propuesta el hotel decidió que evaluaría la propuesta seleccionando los proveedores más adecuados a sus necesidades, sus objetivos y su presupuesto.

Por otra parte el hotel comenzó la implementación dentro de su encuesta de satisfacción la siguiente pregunta relacionada con el aroma del Hotel para ir evaluando el efecto que esta tiene y de esta forma poder hacer los ajustes necesarios con el paso del tiempo.

“ ¿Cree que el aroma que percibe es acorde al concepto del hotel?"

El desarrollo de este proyecto fue un trabajo en equipo donde se contó con la colaboración de los administradores y dueños del hotel, que se vieron interesados con esta propuesta de marketing olfativo, al igual que con el staff, quienes contribuyeron con información y con el mantenimiento de la fragancia en el hotel.

Se le sugirió al hotel como siguiente etapa evaluar aspectos como agradabilidad y fuerza de la fragancia, y formular más preguntas a sus huéspedes relacionadas con el aroma y la marca. 


\section{CAPTULO V}

\section{CONCLUSIONES Y RECOMENDACIONES}

\subsection{Conclusiones de acuerdo a la información obtenida}

Después del desarrollo del presente trabajo a lo largo de los anteriores capítulos se puede concluir que si bien el marketing experimental ha incursionado en algunos sectores, tales como el retail, el automotriz y dl alimentos, el segmento de lujo se muestra como uno de los mercados más interesantes, con perspectivas de crecimiento y oportunidades para desarrollar este tipo de estrategias. Es más, si nos ubicamos en el segmento de lujo aplicado al sector hotelero se puede concluir que el marketing experimental y más específicamente, el marketing olfativo ha desarrollado estrategias con buenos resultados mediante la utilización de fragancias obteniendo una mejora en la percepción de la marca por parte del huésped, aumentando los niveles de fidelización, ventas y mejorando su imagen.

De la misma forma, fue posible concluir que el marketing olfativo hace parte del marketing experimental e involucra al sentido del olfato mediante estrategias definidas que buscan posicionar una marca dentro de un cliente o usuario. Pese a que el olfato es el sentido con mayor poder de recordación es quizá uno de los menos explorados cuando se trata de campañas publicitarias sensoriales. Es por ello que, tal como se expuso en el presente trabajo, actualmente se han identificado estrategias claves de posicionamiento, entre las cuales se encuentra el desarrollo del odotipo.

Vale la pena señalar que el odotipo hace referencia al logo olfativo, a la imagen de marca mediante un aroma o fragancia y que éste sirvió de herramienta en el 
desarrollo del modelo planteado con el objeto de crear identidad en un hotel de lujo.

En tercer lugar, es posible igualmente concluir que un segmento interesante para el marketing olfativo es el sector del lujo, que si bien no está definido bajo un criterio único, podría ser descrito como el sector dentro del cual se encuentran los clientes y usuarios que sienten la necesidad de exclusividad e individualización y donde se encuentran compañías que ofrecen productos y servicios diferenciales con precios generalmente elevados.

En el presente trabajo se centró en el sector de lujo aplicado a la industria hotelera, por ser una industria con perspectivas interesantes de desarrollo y con un gran campo de acción para el marketing olfativo, donde los espacios y sus clientes, debido entre otras cosas a que el huésped de lujo para el presente trabajo, tiene gran interés en este tipo de campañas de diferenciación que le permite vivir y tener contacto con la marca a través de experiencias sensoriales.

Es importante resaltar que el proceso de desarrollo de un odotipo para un hotel de lujo a través del marketing olfativo representa una serie de pasos e involucra al cliente (hotel de lujo) y al desarrollador (empresa o experto en desarrollo de aromas), éste último mediante un proceso de desarrollo puede elaborar una estrategia que permita cumplir con los objetivos y las expectativas del proyecto, mejorando la imagen de la marca y la fidelización del huésped de lujo.

El presente trabajo planteó a manera ilustrativa una metodología que pretende servir de herramienta en el ámbito del marketing sensorial, más específicamente del marketing olfativo, donde se desarrollan una serie de etapas que incluyen el planteamiento de objetivos, la recolección de información, la selección de la fragancia, el método de difusión, los espacios a aromatizar, los costos, la puesta en marcha y una evaluación posterior. Para la generación de esta metodología se 
tuvieron en cuenta los aportes de Curtis, Williams y Horwood $(1994)^{56}$, Kerzner $(2013)^{57}$, Kemp, Hollowood Y Hort (2011) ${ }^{58}$, además de los escritos de Meredith $(2012)^{59}$ sobre la estructura de un proyecto y de Rodríguez $(2013)^{60}$ sobre el desarrollo de un brief de Marketing. Es igualmente significativo resaltar que la experiencia laboral de la autora de este trabajo no solo permitió que esta idea se realice sino que además sirvió de soporte técnico en el planteamiento y aplicación de la metodología al caso.

La metodología propuesta en este trabajo se aplicó de manera práctica a un caso en un hotel boutique en la ciudad de Buenos Aires. Durante el desarrollo de la estrategia de marketing olfativo en el hotel $\mathrm{Bo} \mathrm{Bo}$, se evaluaron diferentes alternativas hasta finalmente seleccionar la más adecuada de acuerdo a las necesidades y expectativas de los involucrados en el proyecto de incorporación de un aroma que representara los valores y marca del hotel mediante el sentido del olfato.

Para cumplir con los objetivos del proyecto de incorporación de aroma en el hotel Bo Bo, se definió como factor unificador la calidez, la sofisticación y la modernidad de forma que la fragancia se basa en notas frutales y vainilla que transmiten este mensaje. La propuesta presentada al hotel Bo Bo incluyó, descripción olfativa de la fragancia relacionada con la marca del hotel y alternativas de fragancia y medios de difusión del aroma. Como complemento de la propuesta olfativa se sugirió el cambio de los amenities para ofrecer una alternativa sensorial más completa en la experiencia del huésped.

\footnotetext{
${ }^{56}$ Ibid Curtis, Williams y Horwood (1994)

${ }^{57}$ Ibid Kerzner (2013)

${ }^{58}$ Ibid Kemp, Hollowood Y Hort (2011)

59 lbid Meredith (2012)

60 lbid Rodríguez (2013)
} 
5.2 Sugerencias para futuros estudios relacionados al tema.

Si bien el presente trabajo sirve de herramienta para la implementación de estrategias que involucren al marketing olfativo en el desarrollo de un odotipo direccionado al sector de hotelería de lujo, también puede servir de herramienta para la incorporación de este tipo de estrategias de diferenciación en otros sectores y en otros mercados.

\subsection{Comentarios generales y personales.}

El marketing sensorial y en especial el marketing olfativo, se han convertido en un sector diferenciado que no muchos conocen y al cual he tenido acceso por mi experiencia laboral, personalmente creo que no falta mucho para que todos nos demos cuenta que de una u otra forma nos encontramos involucrados con experiencias sensoriales que despiertan nuestro interés.

Creo que el sector hotelero es un sector con gran potencial para la aplicación de este tipo de técnicas, donde se puede tener un acercamiento sensorial con el huésped a través del sentido del olfato. 


\section{BIBLIOGRAFIA}

AMA (Asociación Americana de Marketing). Definition of Marketing. Recuperado el 4 de diciembre de 2012 de http://www.marketingpower.com/AboutAMA/Pages/DefinitionofMarketing.as $\underline{\mathrm{px}}$

Arias Díaz, I y Díaz Frigerio, M. (2011). Aplicación del modelo de Marketing Sensorial de Hulten, Broweus y Van Dijk a una empresa chilena de retail. Universidad de Santiago de Chile.

Barrows, C y Powers, T. (2009). Introduction to The Hospitality Industry. New Jersey, Estados Unidos.

Bielbaum, R y Robichaud, J. (2007). Using consumer's sensory experience to achieve strategic market segmentation. volume 122 number II. Cosmetics \& Toiletries. California USA.pp75-80

Bloomberg Business Week. (2010). Scent Branding Sweeps the Fragrance Industry.

Bonadeo, J. (2005) Odotipo Historia Natural del Olfato y su función en la Identidad de Marca. Argentina.

Burr, C. Hotels'New Custom Scents. Recuperado el4 de junio de 2008 de http://www.travelandleisure.com/articles/hotels-new-custom-scents.

Campuzano Garcia, Susana. (2003). El Universo del lujo: Una Visión Global y Estratégica de los Amantes del Lujo. Madrid España: McGraw-Hill.

Criterios de Clasificación de Hoteles. Recuperado el 5 de Febrero de 2013 de http://www.hotelstars.eu/es/index.php?open=Criteria.

Curtis, T., Williams, D y Horwood, E. (1994). Introduction to perfumery. London.

Danzinger, P. (2005). Marketing Luxury to the Masses as well as the classes. Estados Unidos: Dearborn Trade Publishing 
Davies, B. J., Kooiman, D. and Ward, P. (2003), "The Sweet Smell of Success: Olfaction in Retailing", Journal of Marketing Management, Vol. 19 Issue 5/6 (July)

Escobar, E. (2011). El Confort como una importante dimensión de Calidad en la hotelería Vol 4, No9. Escuela de hoteleria y Turismo de Camaguey.

Familia Olfativa. Osmoz. Recuperado de http://es.osmoz.com/enciclopedia/familias- olfativas. 2013.

Gallego, J.F. (2009). Marketing para hoteles y Restaurantes, los nuevos Escenarios. Magallares España: Editorial Paraninfo

Gaygen, D y Hedge, A. (2008). Effect of acute exposure to a complex Fragrance on lexical decision. Department of Design and Environmental Analysis. Cornell University. Ithaca Estados Unidos.

Gómez, M. y García, C. (2010). "Nuevas tendencias en el punto de venta: el marketing sensorial", Distribución comercial y comportamiento del consumidor", Cátedra Fundación Ramón Areces de Distribución Comercial, Universidad de Oviedo

Hulten, B., Broweus, N. y Van Dijk, M. (2009). Sensory Marketing. United Kingdom: Palgrave Macmillan.

Ilmberger, J., Heuberger, E., Mahrhorfer, C., Dessovic, H., Kowarik, D y Buchhbauer, G. (2000). The influence of essential Oils on human Attention. Alertness.

Información General del Hotel Bo Bo. Recuperado el 10 de julio de http://www.bobohotel.com/

Kemp, S. E., Hollowood, T. y Hort J. (2011). Sensory Evaluation. A Practical Handbook. Wiley Blackwell.

Kerzner, H. (2013). Project management: $A$ systems approach to planning, Scheduling, and controlling. Séptima edición. Nueva York: Publicado por John Wiley \& Sons.

Kimpton Hotels \& Restaurants. Recuperado de https://www.kimptonhotels.com/. 2013.

Kotler, P. (2007). Marketing: Versión para Latinoamérica. 11를 edición. Mexico: 
Pearson

Lindstrom, M. (2005). Brand Sense: Build Powerful Brands through Touch, Taste, Smell, sight and sound. United Kingdom: British library cataloguing. Creative Print and design.

Luxury Hotels Partners. Recuperado el 3 de marzo de 2013 de http://www.luxuryhotelpartners.com/.

Luxury goods market predicted to grow six to seven percent in 2012, defying global turmoil and spreading to new markets, according to spring update of Bain \& Company's luxury goods worldwide market study. 15 de mayo de 2012. Recuperado de Brain \& Company. http://www.bain.com/about/press/pressreleases/luxury-goods-market-predicted-to-grow-six-to-seven-percent-in2012.aspx

Marketing Olfativo Tu Marca Huele Bien. Recuperado el 4 de julio de 2013 de http://www.marketingyfinanzas.net/2013/07/marketing-olfativo-tu-marcahuele-bien-2/.

Martinez de Cestafe, N. (2006). Documento De Trabajo. El Mercado De La Cosmética De Lujo: La Relación entre la marca y la distribución selectiva en Alemania. Tesina Fin de Carrera del European Business Programme (EBP España) de la Cámara de Comercio e Industria de Madrid. Universidad Antonio de Nebrija y University of Applied Sciences Münster. España.

Meredith, J. R y Mantel, S. (2012). Project Management A Managerial Approach. Nueva York: Publicado por John Wiley \& Sons. pp 24.

Mogelonsky, L. (2013). The sense of smell can be harnessed as a way to further guest satisfaction and develop a loyal consumer base for hoteliers.

En Hotel News Now. Recuperado de http://www.hotelnewsnow.com/Article/9850/Ambient-scent-marketingactivates-olfactory

Priscilla Paoli, F. (2008). El marketing olfativo como aplicación del marketing Experimental, uso de aromatizantes de venta minorista. ITERCOM sociedad Brasilera de estudios interdisciplinarios de comunicación. XIII Congreso de ciencias de la comunicación en la región sudeste. Sao Pablo.

Programme D'accreditation Pour La Realisation Des Inspections De Classement Des Hebergements Touristiques Marchands. (2009) Document INS REF 20. Révision 05. Recuperado el 23 de febrero de 2013 de http://www.cofrac.fr/documentation/INS-REF-20. 
Rodríguez, R. (2003). Definición De Investigación De Mercados. Marketing E Investigación De Mercado 2 ${ }^{\text {a }}$ Parte. Recuperado de http://www.gestiopolis.com/canales/demarketing/articulos/68/mktinv2.htm

Rossi, M. E. y Leon, F. (2000). El Libro De Velas. Editorial Albatros. Buenos Aires Argentina.

Sandilands, T. Small business. Definition of Retail Marketing. Recuperado de http://smallbusiness.chron.com/definition-retail-marketing-40196.html . 2013.

Scent Marketing. Recuperado el 20 de octubre de http://www.scentair.com/whyscent-scent-marketing/

Sherman, E., Marthur A. y Belk S.R. (1997), "Store environment and consumer purchase behavior: mediatina role of consumer emotions", Psychology \& Marketing. Wiley Periodicals, Inc., A Wiley Company

Shiffman, L. (2005). 8ª edición. Comportamiento del consumidor. México: Prentice Hall.

Schmitt, B. (2002). Marketing Experimental. Brazil: Editorial Nobel

Smith, V. (1989). Second Edition Hosts and Guests The Antropology of tourism. Universidad de Pennsylvania.

Suarez Gómez, M y Rozano, M. (2006). La influencia del aroma en la Percepción del establecimiento comercial. Universidad Autónoma de Madrid. España.

Suarez Morales, L. (2012). Trabajo de Grado: Marketing Sensorialy sus Tendencias. Facultad de Administración. Colegio de Estudios Superiores de Administración (CESA). Colombia.

Sutton, P. (2011). Multisensory Experiential Marketing. Head of Multisensory Innovation. Recuperado de http://eventige.com/multisensory-experientialmarketing/

The Scent hotel. Recuerado el 3 de marzo de 2013 de http://www.thescenthotel.com/about-en.html.

The marketer the chartered instituted of marketing. Smell sells: scent marketing 
(2011). Recuperado de http://www.themarketer.co.uk/archives/trends/scentmarketing/.

Top Hotels Projects. Recuperado el 22 de enero de 2013 de http://www.tophotelprojects.com/es/acerca-de-nosotros.

Top 10 de los hoteles ecológicos del mundo. Recuperado el 5 de agosto de 2013. http://www. mundo-geo.es/viajes-y-expediciones/viajes/top-10-de-loshoteles-ecologicos-del-mundo

Vosshall L. y Carandini M. (2009). Sensory Systems. Laboratory of Neurogenetics and Behavior. The Rockefeller University. United States: Elsevier Ltda. Recuperado de http://vosshall.rockefeller.edu/smellstudy.php

Wright. L T. Newman A y Dennis C. (2006). Enhancing consumer empowerment. European Journal of Marketing.ed 40, 9/10, 925-935. 


\section{ANEXOS}

ANEXO 1 - CARTA DE AUTORIZACION PARA LA IMPLEMENTACION DEL TRABAJO EN EL HOTEL BO BO 
"Declaro bajo juramento que esta tesis fue elaborada por mí, que no utilicé ningún otro material que no haya dado a conocer en las referencias y que no utilicé frases o párrafo de otros autores, que este trabajo de tesis nunca ha sido presentado ante un comité de evaluación de tesis y que no transgreda derechos de terceros." 